\title{
Mapping the 'early salinity response' triggered proteome adaptation in contrasting rice genotypes using iTRAQ approach
}

Nita Lakra', Charanpreet Kaur ${ }^{1}$, Sneh Lata Singla-Pareek ${ }^{2}$ and Ashwani Pareek ${ }^{1 *}$ (D)

\begin{abstract}
Background: To delineate the adaptive mechanisms operative under salinity stress, it is essential to study plant responses at the very early stages of stress which are very crucial for governing plant survival and adaptation. We believe that it is the initial perception and response phase which sets the foundation for stress adaptation in rice seedlings where plants can be considered to be in a state of osmotic shock and ion buildup.

Results: An isobaric Tags for Relative and Absolute Quantitation (iTRAQ) approach was used to analyze the pre-existing differences as well as the very early salt shock responsive changes in the proteome of seedlings of contrasting rice genotypes, viz salt-sensitive IR64 and salt-tolerant Pokkali. In response to a quick salt shock, shoots of IR64 exhibited hyperaccumulation of $\mathrm{Na}^{+}$, whereas in Pokkali, these ions accumulated more in roots. Interestingly, we could find 86 proteins to be differentially expressed in shoots of Pokkali seedlings under non-stress conditions whereas under stress, 63 proteins were differentially expressed in Pokkali shoots in comparison to IR64. However, only, 40 proteins under non-stress and eight proteins under stress were differentially expressed in Pokkali roots. A higher abundance of proteins involved in photosynthesis (such as, oxygen evolving enhancer proteins OEE1 \& OEE3, PsbP) and stress tolerance (such as, ascorbate peroxidase, superoxide dismutase, peptidyl-prolyl cis-trans isomerases and glyoxalase II), was observed in shoots of Pokkali in comparison to IR64. In response to salinity, selected proteins such as, ribulose bisphosphate carboxylase/oxygenase activase, remained elevated in Pokkali shoots. Glutamate dehydrogenase - an enzyme which serves as an important link between Krebs cycle and metabolism of amino acids was found to be highly induced in Pokkali in response to stress. Similarly, other enzymes such as peroxidases and triose phosphate isomerase (TPI) were also altered in roots in response to stress.
\end{abstract}

Conclusion: We conclude that Pokkali rice seedlings are primed to face stress conditions where the proteins otherwise induced under stress in IR64, are naturally expressed in high abundance. Through specific alterations in its proteome, this proactive stress machinery contributes towards the observed salinity tolerance in this wild rice germplasm.

Keywords: iTRAQ, Proteomics, Pokkali, Rice, Salinity, Seedlings

\footnotetext{
* Correspondence: ashwanip@mail.jnu.ac.in

${ }^{1}$ Stress Physiology and Molecular Biology Laboratory, School of Life Sciences,

Jawaharlal Nehru University, New Delhi 110067, India

Full list of author information is available at the end of the article
} 


\section{Backgound}

Soil salinity is one of the major hurdles faced by agricultural scientists throughout the world as it severely limits crop productivity and yield (Pareek et al. 2010; Joshi et al. 2018). Excessive accumulation of $\mathrm{Na}^{+}$in the soil inhibits absorption of moisture and mineral nutrients, resulting in buildup of toxic ions and reactive oxygen species (ROS) in plants (Kim et al. 2008). These toxic byproducts can diminish enzyme activity or even degrade cellular proteins. To overcome this, plants have acquired dynamic responses at various levels to facilitate their survival under stress (Munns and Tester 2008). In plants, salinity triggers the expression of genes that function in both salt response and in increasing salt tolerance. Though all plants try to adjust to these unforeseen situations, but it is the timely and well-coordinated response acquired in selected genotypes which leads to their successful adaptation and hence, survival under stress (Lakra et al. 2018). On the other hand, susceptible species succumb to stress due to their inability to efficiently channelize resources towards stress management. An understanding of the behavior of both tolerant and susceptible species is thus, worth investigating to identify differences at molecular, physiological and biochemical levels under stress conditions which can then be employed to engineer stress tolerance in plants.

Rice (Oryza sativa L.) is a major cereal crop and is a key source of dietary starch for about half of the population (Fageria 2007). Its growth and productivity is significantly affected by salinity conditions and thus, rice is considered to be salt-sensitive with degree of its sensitivity varying during different growth phases (Moradi and Ismail 2007). The cultivation practice for rice known as SRI (System of Rice Intensification), involves transplantation of young seedlings (8-12 days old; with 2-3 leaf stage) to the field so as to preserve their potential for tillering and rooting ability. Thus, this seedling stage is considered to be very important for governing the fate of successful crop production.

IR64 is a semi-dwarf and high yielding, variety of indica rice which is moderately sensitive to salinity whereas Pokkali, another indica rice having a high protein content, medicinal property, high amylase content (good for the diabetic patients) and peculiar taste (Agriculture Department, Government of Kerala; http://sites.cdit.org/wto/ index.php/pokkali-rice), is a wild landrace with unique saline tolerant genes (Thomson et al. 2010; Waziri et al. 2016; Nutan et al. 2017). It is cultivated in an organic way accompanied by integrated farming with prawn culture in the water logged coastal regions of Kerala in Southern India inundated with saline sea water in the field (Vijayan 2016). These two genotypes, owing to differences in their response to salt stress, have been extensively used as research material by plant scientists. Gene expression studies have revealed that salt tolerance of Pokkali may be due to constitutively high expression of several genes that contribute to salinity tolerance, such as CaMBP, glutathione transferases, late embryogenesis abundant proteins, V-ATPase, OSAP1 zinc finger protein and HBP1B transcription factor (TF) but these are stress inducible in IR64 (Kumari et al. 2009; Soda et al. 2013). Interestingly, recent RNA seq-based transcriptome studies in IR64 (salt sensitive), Pokkali (salt-tolerant) and N22 (drought-tolerant) genotype have revealed that a total of 801 transcripts in N22 and 507 in Pokkali to be exclusively differentially expressed under stress conditions (Shankar et al. 2016). Gene ontology studies further suggested an enrichment of transcripts involved in abiotic stress response and regulation of gene expression in these stress-tolerant rice cultivars. Specifically, members of bHLH and $\mathrm{C}_{2} \mathrm{H}_{2}$ transcription families in Pokkali exhibited differential regulation under salinity and desiccation stresses, respectively and transcripts involved in wax and terpenoid metabolism were also found to be up-regulated. However, at proteome level, not much is still known about the differential response of these genotypes. Proteome studies in other rice varieties though have been carried out. For instance, $\mathrm{Xu}$ et al. (2015) have studied changes in protein profiles in $J a$ ponica rice cultivar Zhonghua11 (ZH11) after $24 \mathrm{~h}$ of salinity stress and identified 56 proteins to be differentially regulated with 16 of them being enriched in antioxidant pathways, oxidative phosphorylation and photosynthesis. Further, comparative proteome analysis of two contrasting African rice genotypes has also been carried out indicating proteins involved in redox homeostasis, stress, and signaling categories to be differentially responsive in the sensitive and tolerant genotypes (Damaris et al. 2016).

Recently, we have reported a comparative temporal proteome analysis of Pokkali and IR64 genotypes in response to salinity stress using 2D-DIGE (Lakra et al. 2018). Our findings suggested that Pokkali proteome exhibits increased expression of photosynthesis-related proteins after $15 \mathrm{~min}$ and $2 \mathrm{~h}$ of salinity stress in contrast to IR64 which shows greater perturbations in metabolism-related proteins during this phase. However, at later stages viz. 24-72 h, stress acclimation response is induced in Pokkali, and at this time, proteins which were found to be early induced in Pokkali can be seen to be induced in IR64, suggesting a late induction of stress response in IR64. The study thus indicated towards important differences in the cellular machinery of these genotypes and suggested that early stress response forms an important component of plant stress adaptation machinery which needs to be studied in details to decipher the basis of stress tolerance in plants. Therefore, in the present work, we have studied the response of rice seedlings to very early stress, a state where plants can be considered to be in a state of osmotic shock in response to stress. The stress-tolerant Pokkali and stress-sensitive IR64 rice genotypes were 
subjected to $200 \mathrm{mM} \mathrm{NaCl}$ treatment for $2 \mathrm{~h}$, and proteome profile was elucidated using the isobaric Tags for Relative and Absolute Quantitation (iTRAQ) approach (Fig. 1). iTRAQ which is a non-gel-based quantitative proteomics technique overcomes some of the drawbacks otherwise observed with 2-DE (Zieske 2006) and can be used to relatively quantify peptides at a global level (Ghosh et al. 2013). Proteome profiles of shoot and root tissues of both genotypes were studied separately to dissect primary and secondary signals generated by plants upon sensing salt stress. Roots serve as the primary site for salinity perception which then communicates these signals to shoots, the energy source of the developing seedlings. We specifically selected $2 \mathrm{~h}$ duration of stress treatment since we believe that it is the initial crucial phase of stress response which sets the foundation for stress adaptation in selected genotypes. Gaining an understanding of early triggering response is essential to unravel the basis of stress tolerance in plants. Our findings suggested that Pokkali proteome has an abundance of stress-responsive proteins under non-stress conditions especially the photosynthesis-related proteins. Importantly, these proteins exhibit higher expression in Pokkali than IR64 even under stress thereby contributing towards better adaptation of the latter towards stress.

\section{Results}

Determination of physiological perturbations in Pokkali and IR64 seedlings in response to salinity stress

Ten-day old Pokkali and IR64 seedlings were treated for $2 \mathrm{~h}$ with $200 \mathrm{mM} \mathrm{NaCl}$, and $\mathrm{Na}^{+}$accumulation was measured

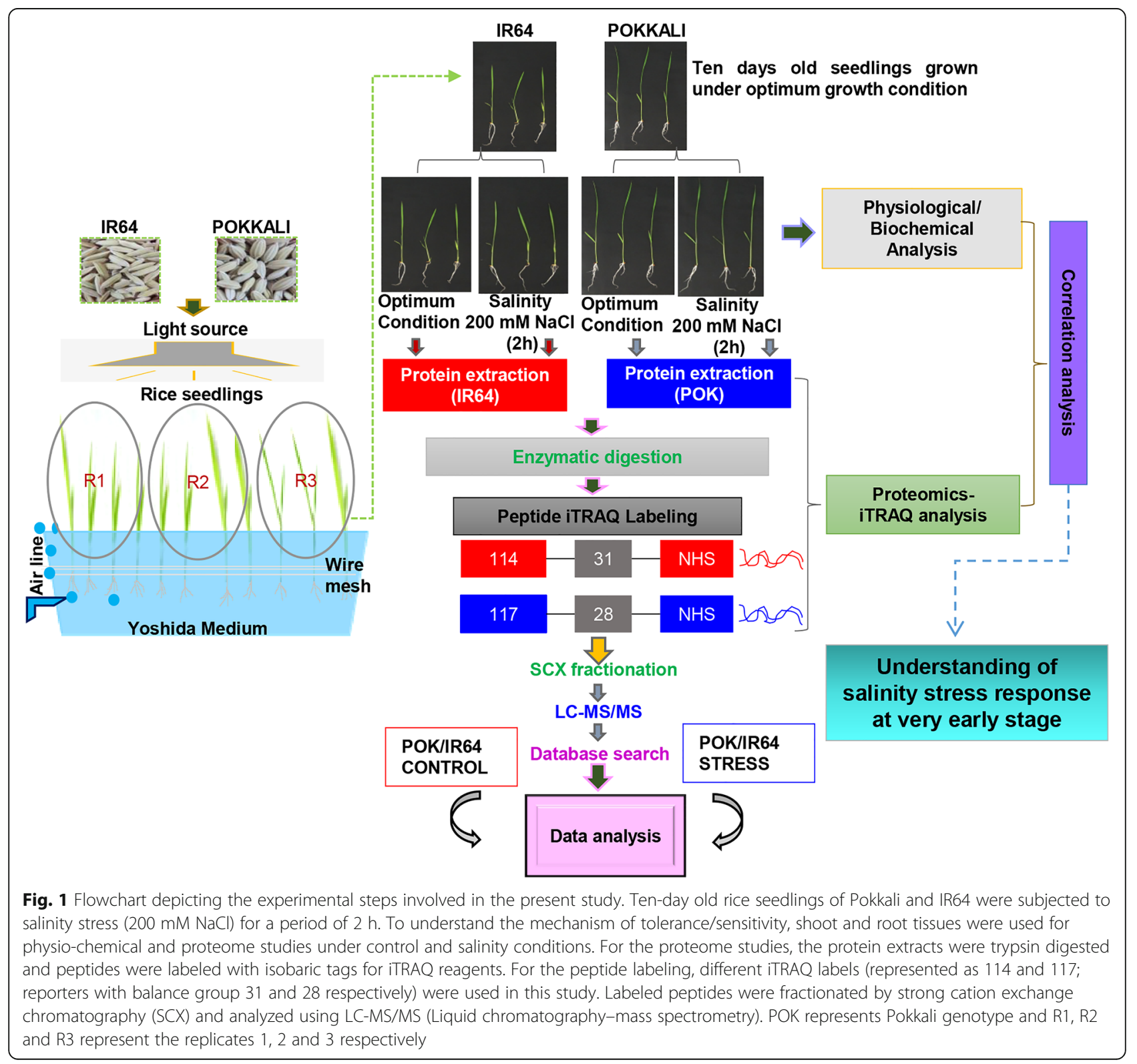


in the shoot and root tissues. Under control conditions, $\mathrm{Na}^{+}$ levels were similar in both the genotypes (both roots and shoots). However, after $2 \mathrm{~h}$ of salinity treatment, $\mathrm{Na}^{+}$levels increased by 6-folds ( 950.8 to $5674.3 \mathrm{ppm}$ ) and by 3.38-folds (777.6 to $2629.6 \mathrm{ppm}$ ) in shoots of IR64 and Pokkali respectively as compared to their untreated controls. Overall, sodium accumulation was 2.2-fold higher in IR64 shoots (5674.3 ppm) in comparison to Pokkali (2629.6 ppm) after 2 $\mathrm{h}$ of stress (Fig. 2a). By contrast, whereas $\mathrm{Na}^{+}$levels increased by 28-folds in roots of IR64 seedlings (2038.41 to $57,426.71 \mathrm{ppm})$ after $2 \mathrm{~h}$ of the $\mathrm{NaCl}$ treatment, Pokkali roots exhibited a much higher increase $(\sim 31$-folds $)$ in $\mathrm{Na}^{+}$ levels (1919.71 to 59,426.71 ppm) under similar conditions
(Fig. 2a). Change in $\mathrm{Na}^{+} / \mathrm{K}^{+}$ratio was found to be 2.63 -fold higher in IR64 shoots but 2.4-fold lower in roots of IR64 seedlings as compared to corresponding tissues of Pokkali (Fig. 2a). Further, change in $\mathrm{K}^{+} / \mathrm{Na}^{+}$ratio was found to be 2.63-fold higher in Pokkali shoots but 2.15-fold lower in roots of Pokkali seedlings as compared to corresponding tissues of IR64 (Fig. 2b). However, percent change in electrolyte leakage (relative ion leakage) was $\sim 1.5$-fold higher in IR64 seedlings then Pokkali after $2 \mathrm{~h}$ of salinity stress (Fig. 2c). Further, CoroNa dye staining under control and stress conditions indicated higher $\mathrm{Na}$ accumulation in Pokkali roots at $2 \mathrm{~h}$ of stress in comparison to IR64 (Fig. 2d). We also measured root

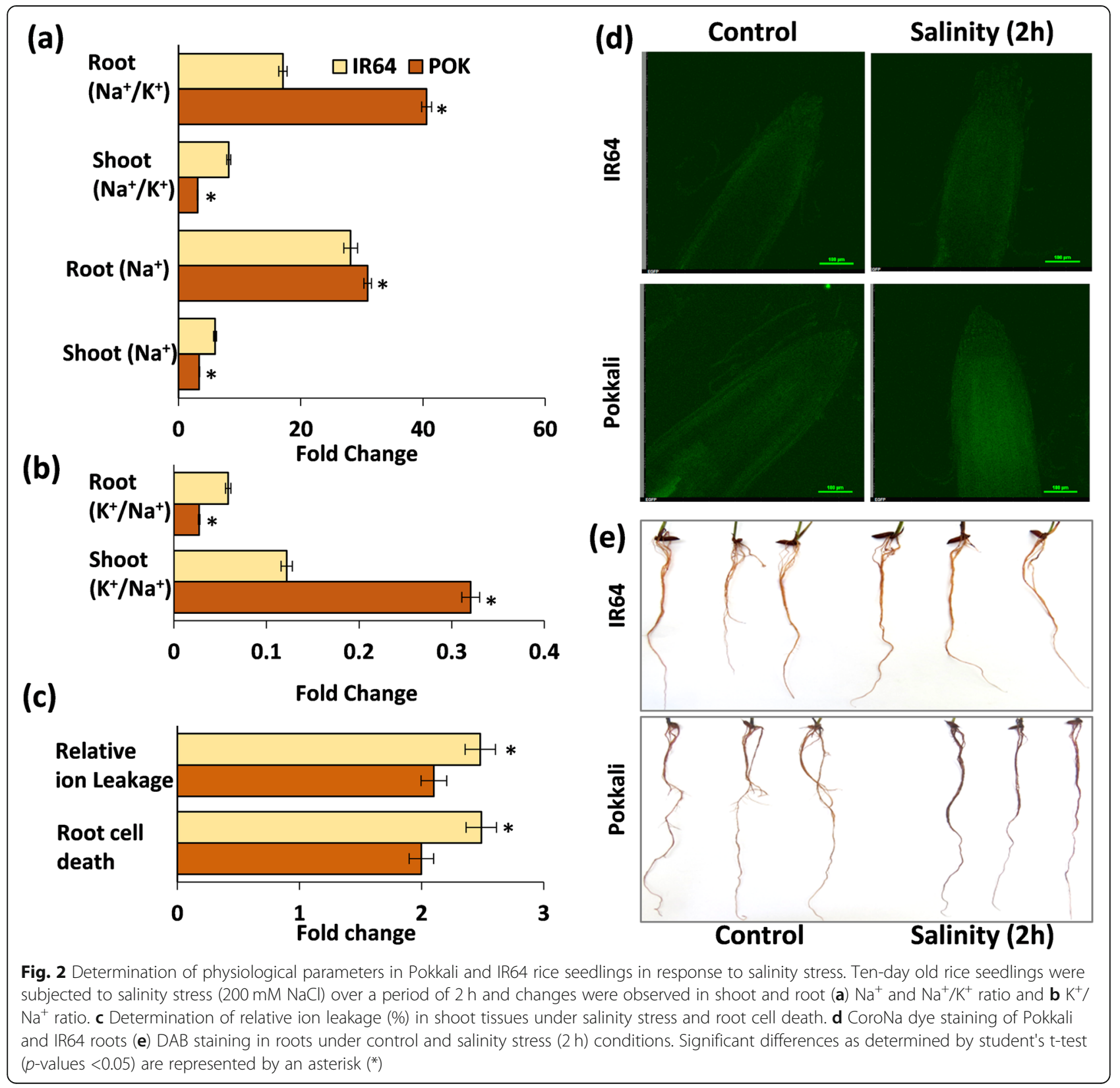


cell death and found that the uptake of the Evan blue dye (indication of dead cells) was more in IR64 than Pokkali (Additional file 1: Figure S1). Specifically, the root cell death rate was 1.5 -fold pronounced in IR64 then Pokkali under salinity stress (Fig. 2c).

\section{Determination of reactive oxygen species (ROS) levels in response to salinity stress}

Since stress is almost always accompanied by the production of reactive oxygen species (ROS), we checked the levels of $\mathrm{H}_{2} \mathrm{O}_{2}$ in both IR64 and Pokkali roots using DAB (3,3-diaminobenzidine) stain which indicates the levels of $\mathrm{H}_{2} \mathrm{O}_{2}$ through development of a dark brown color. Interestingly, we observed a higher DAB staining in Pokkali roots as compared to IR64 indicating higher $\mathrm{H}_{2} \mathrm{O}_{2}$ levels in Pokkali in response to salinity stress (Fig. 2e and Additional file 2: Figure S2). Taken together the present study reveals that within $2 \mathrm{~h}$ of salinity stress enough $\mathrm{Na}^{+}$is build up in tissues which are affecting in turn, differentially affects the various physiological parameters between IR64 and Pokkali.

\section{iTRAQ based proteome analysis in seedlings of Pokkali and IR64 under control and salinity stress conditions}

Our previous study on comparative temporal proteomics of Pokkali and IR64 rice seedlings has revealed some important physiological and proteome changes occurring in Pokkali under stress conditions (Lakra et al. 2018). However, in this work, changes in Pokkali and IR64 proteomes at early duration of stress were not investigated in detail and also changes in proteomes of two genotypes under non-stress conditions were not explored. Hence, to elucidate variations in the proteome of Pokkali and IR64 under control conditions as well as under stress, we carried out an iTRAQ-based proteome analysis and determined the proteins being differentially expressed in Pokkali in comparison to IR64 under normal and stress conditions. The proteins were detected at greater than 95\% confidence with ProtScore cut off $>1.3$. A total of 422 proteins under non-stress and 445 proteins under stress conditions were detected in the shoot tissues of Pokkali. 183 proteins were only detected under control conditions, 206 under only salt stress and 239 under both the conditions (Fig. 3a). Whereas in roots, of the 330 proteins detected under control (non-stress) conditions and 287 proteins detected under salinity stress, 153 were common to both (Fig. 3a). Further, peptide sequence coverage which indicates the percentage of the protein sequence covered by the identified peptides, was determined for the proteins. Maximum number of proteins showed $10-40 \%$ sequence coverage (Fig. $3 \mathrm{~b})$. Further, around 100-150 proteins in each sample were identified using only a single peptide. About 74108 proteins had two peptide hits corresponding to the identified proteins and only 2-37 proteins had more than 11 identified peptides (Fig. 3c).

The differentially expressed proteins obtained from iTRAQ analysis were then quantitatively analyzed using appropriate selection criteria. The $p$-value threshold was kept 0.05 . Fold change of greater than one in protein expression of Pokkali vs IR64 proteins was considered to be upregulated and less than one was taken to be downregulated. Based on these filters, we could find 86 proteins to be differentially expressed in shoots of Pokkali seedlings under non-stress conditions whereas under stress, 63 proteins were differentially expressed in Pokkali shoots in comparison to IR64 (Table 1, a-d). In roots, however lower number of proteins were obtained. Forty proteins under non-stress and eight proteins under stress were differentially expressed in Pokkali roots (Table 2, a-d). Interestingly, none of these identified root proteins were common between control and stressed proteomes of Pokkali. The differentially expressed proteins in both root and shoot tissues of Pokkali under control and salinity stress conditions have been listed in Tables 1 and 2 .

\section{Functional classification of differentially abundant proteins in seedlings of Pokkali under control and stress conditions}

In order to analyze the differential response of Pokkali and IR64, differentially expressed proteins were classified into functional categories. Eighteen major categories of proteins were observed in the shoot proteome of Pokkali whereas root proteome comprised of 17 major functional categories (Fig. 4a, b). Under non-stress conditions, proteins belonging to the protein metabolic process-related and photosynthesis/ETC/Calvin/light reaction-related categories were found to be most enriched; comprising $22 \%$ and $13 \%$ of the total differential shoot proteome, respectively. The third major category was of stress-responsive proteins and those involved in cellular organization/cell cycle, both comprising $8 \%$ of the differential shoots proteome under control conditions. Interestingly, these categories remained enriched even after $2 \mathrm{~h}$ of stress (Fig. 4a).

Inspection of differential root proteome of Pokkali under non-stress conditions revealed an abundance of metabolic process-related proteins which formed 13\% of the total differential proteome followed by 'function not assigned' category (Fig. 4b). The other major category being differentially regulated was found to be of peroxidase (11\%) which was followed by category of stress-responsive and amino acid metabolism related proteins (8.5\%). However, in the stressed root proteome of Pokkali, functional categories such as, peroxidase family proteins, PS.calvin cycle.TPI and signaling proteins were found to be selectively enriched (Fig. 4b). 


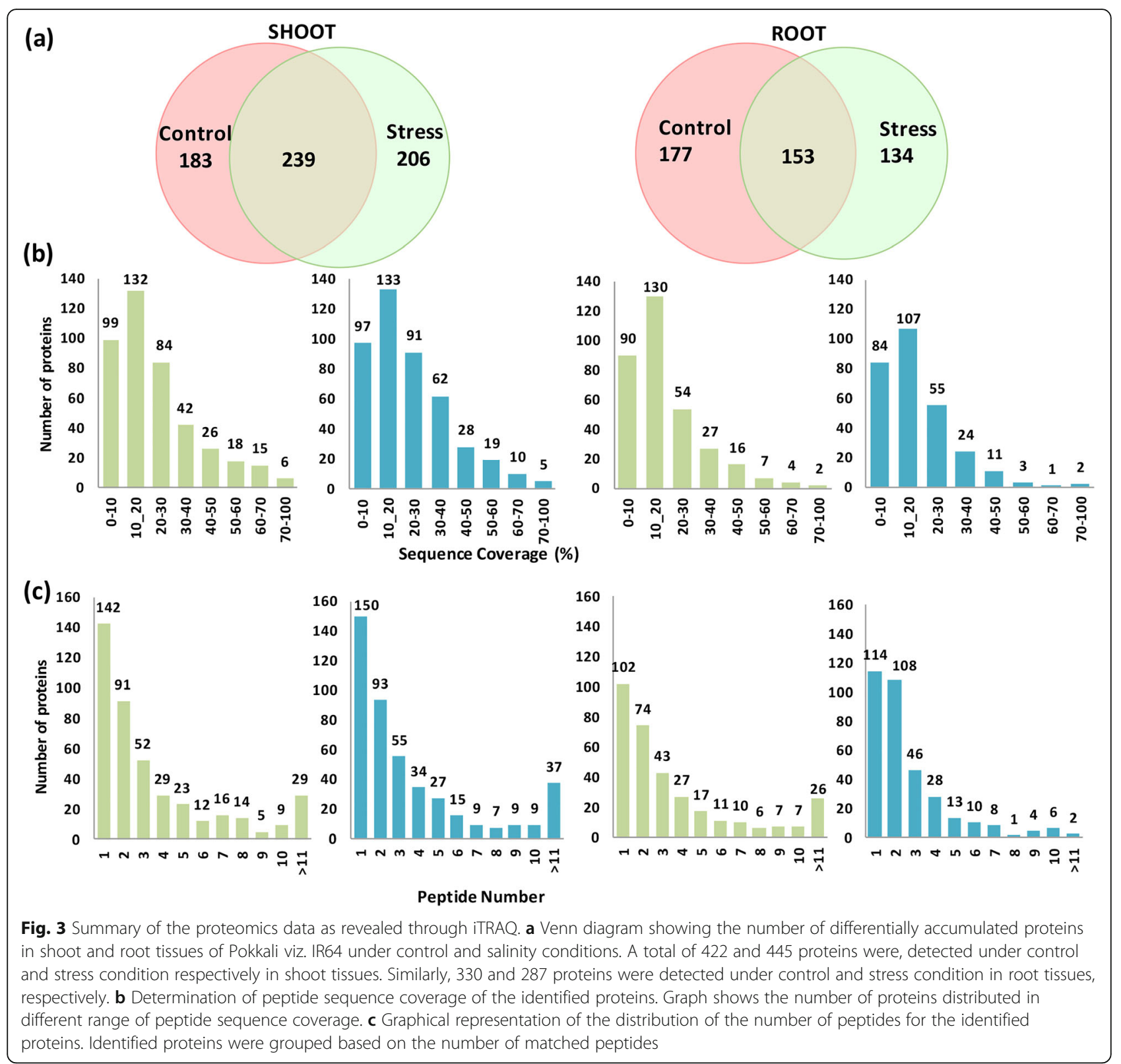

\section{Proteins with very high abundance in Pokkali proteome} under non-stress conditions

Considering the fact that the unstressed proteome of Pokkali had higher abundance of many proteins belonging to different categories in comparison to IR64, we specifically analyzed those proteins which differed markedly in their abundance in the two genotypes and thus, used $>60$-fold change criteria for selection of those proteins in the differential proteome. Among the shoot proteins with $>60$-fold change expression in Pokkali, are several abiotic and biotic stress responsive candidates such as glyoxalase II, superoxide dismutase, peptidyl-prolyl cis-trans isomerase and dirigent protein 22 (Additional file 3: Table S1). Further, even a photosynthetic protein, phytocyanin-related protein Pn14, was found to be highly expressed in Pokkali. Furthermore, a ferredoxin-dependent glutamate synthase protein showed 64-fold increase in Pokkali in comparison to IR64 under control conditions.

In contrast to shoot proteome, which had 27 proteins with greater than 60-fold expression, root proteome had only five such proteins, which included, adenine phosphoribosyltransferase 1, peroxidase, chaperonin and L-asparaginase (Additional file 3: Table S1). Peroxidases and chaperonins are known to be the key players in stress response. Thus, Pokkali proteome appeared to possess huge differences in abundance of some proteins 
Table 1 Differentially expressed proteins in shoot tissues of pokkali w.r.t IR64

\begin{tabular}{|c|c|c|c|c|c|c|}
\hline Protein identity & $\%$ coverage & Peptides & $\begin{array}{l}\text { POK } \\
\text { IR64 }\end{array}$ & pvalue & MSU ID & Protein function \\
\hline \multicolumn{7}{|l|}{ (A) Control UP } \\
\hline $\begin{array}{l}\text { Oxygen-evolving enhancer } \\
\text { protein } 1 \text {, chloroplast }\end{array}$ & 70 & 60 & 8.5507 & 0.0022 & LOC_Os01g31690.1 & $\begin{array}{l}\text { PS.lightreaction.photosystem II.PSII } \\
\text { polypeptide subunits' }\end{array}$ \\
\hline PsbP & 73.6 & 48 & 6.0813 & 0.01 & LOC_Os07g04840.1 & $\begin{array}{l}\text { PS.lightreaction.photosystem II.PSII } \\
\text { polypeptide subunits' }\end{array}$ \\
\hline $\begin{array}{l}\text { Inorganic pyrophosphatase, } \\
\text { putative }\end{array}$ & 61.5 & 26 & 2.421 & 0.0041 & LOC_Os02g52940.2 & $\begin{array}{l}\text { 'nucleotide metabolism.phosphotransfer } \\
\text { and pyrophosphatases.misc' }\end{array}$ \\
\hline Salt stress root protein RS1 & 76.5 & 19 & 6.6069 & 0.0013 & LOC_Os01g13210.2 & 'stress.abiotic.drought/salt' \\
\hline Expressed protein & 71.5 & 13 & 1.4588 & 0.0226 & LOC_Os10g18340.2 & 'not assigned.unknown' \\
\hline Thioredoxin, putative & 41.3 & 22 & 6.1376 & 0.0349 & LOC_Os12g08730.1 & 'redox.thioredoxin' \\
\hline Superoxide dismutase [Cu-Zn] & 62.6 & 19 & 99.0832 & 0.0032 & LOC_Os08g44770.1 & 'redox.dismutases and catalases' \\
\hline Peptidyl-prolyl cis-trans isomerase & 46.4 & 10 & 5.1051 & 0.0327 & LOC_Os05g01270.1 & 'cell.cycle.peptidylprolyl isomerase' \\
\hline $\begin{array}{l}\text { Thylakoid lumenal protein, } \\
\text { putative }\end{array}$ & 54.7 & 8 & 1.3932 & 0.0174 & LOC_Os10g35810.1 & biological process \\
\hline $\begin{array}{l}\text { NAD dependent epimerase/ } \\
\text { dehydratase }\end{array}$ & 45.9 & 7 & 16.4437 & 0.0008 & LOC_Os05g01970.5 & 'protein.degradation' \\
\hline $\begin{array}{l}\text { ATP-dependent Clp protease } \\
\text { ATP-binding subunit }\end{array}$ & 14.5 & 6 & 3.8019 & 0.0046 & LOC_Os04g32560.1 & 'protein.degradation.serine protease' \\
\hline Peptidyl-prolyl cis-trans isomerase & 31.7 & 5 & 20.3236 & 0.0225 & LOC_Os06g45340.1 & 'protein.folding' \\
\hline $\begin{array}{l}\text { RAD23 DNA repair protein, } \\
\text { putative }\end{array}$ & 24.9 & 4 & 99.0832 & 0.0265 & LOC_Os06g 15360.1 & 'DNA.repair' \\
\hline $\begin{array}{l}\text { Thylakoid lumenal } 16.5 \mathrm{kDa} \\
\text { protein }\end{array}$ & 19.3 & 5 & 1.0666 & 0.0043 & LOC_Os06g49160.1 & Biological process \\
\hline $\begin{array}{l}\text { Calvin cycle protein } \mathrm{CP} 12 \text {, } \\
\text { putative, }\end{array}$ & 44.4 & 5 & 7.8705 & 0.0334 & LOC_Os01g19740.1 & 'PS.calvin cycle' \\
\hline Elongation factor protein & 38.9 & 8 & 10.2802 & 0.0371 & LOC_Os07g42300.1 & 'protein.synthesis.elongation' \\
\hline $70 \mathrm{kDa}$ heat shock protein & 31.1 & 14 & 2.5351 & 0.0029 & LOC_Os12g14070.1 & 'stress.abiotic.heat' \\
\hline Remorin, putative, expressed & 38.4 & 3 & 1.6596 & 0.0182 & LOC_Os04g45070.1 & $\begin{array}{l}\text { 'RNA.regulation of transcription.putative } \\
\text { transcription regulator' }\end{array}$ \\
\hline Proteasome subunit alpha type & 31.7 & 3 & 3.0479 & 0.0444 & LOC_Os11g40140.1 & 'protein.degradation.ubiquitin.proteasom' \\
\hline Oryzain alpha & 10.3 & 4 & 1.4588 & 0.0025 & LOC_Os04g55650.1 & 'protein.degradation.cysteine protease' \\
\hline acyl CoA binding protein, putative & 79.1 & 5 & 1.1588 & 0.0204 & LOC_Os06g02490.1 & $\begin{array}{l}\text { 'lipid metabolism.FA synthesis and FA } \\
\text { elongation.acyl-CoA binding protein' }\end{array}$ \\
\hline Lipid transfer protein-like & 14.5 & 3 & 13.9316 & 0.033 & LOC_Os08g42040.1 & 'lipid metabolism.lipid transfer proteins etc' \\
\hline Uridylyltransferase-related & 23.9 & 3 & 1.2942 & 0.0067 & LOC_Os08g14440.2 & 'amino acid metabolism' \\
\hline Nucleoside diphosphate kinase 1 & 34.2 & 2 & 99.0832 & 0.0265 & LOC_Os07g30970.1 & $\begin{array}{l}\text { 'nucleotide metabolism.phosphotransfer } \\
\text { and pyrophosphatases.nucleoside } \\
\text { diphosphate kinase' }\end{array}$ \\
\hline DnaK family protein & 16.5 & 3 & 3.767 & 0.0049 & LOC_Os02g53420.1 & 'stress.abiotic.heat' \\
\hline Hydroxyacylglutathione hydrolase & 14.3 & 2 & 99.0832 & 0.019 & OC_Os03g21460.1 & $\begin{array}{l}\text { 'Biodegradation of Xenobiotics. } \\
\text { hydroxyacylglutathione } \\
\text { hydrolase' }\end{array}$ \\
\hline H0801D08.11 protein & 14.3 & 2 & 87.9023 & 0.0185 & LOC_Os04g58240.1 & transport \\
\hline Kinase, pfkB family, & 22 & 2 & 2.884 & 0.0377 & LOC_Os08g02120.1 & $\begin{array}{l}\text { 'major CHO metabolism.degradation. } \\
\text { sucrose.fructokinase' }\end{array}$ \\
\hline Histone $\mathrm{H} 2 \mathrm{~B}$ & 16.5 & 2 & 1.1803 & 0.0033 & LOC_Os05g49860.1 & $\begin{array}{l}\text { 'DNA.synthesis/chromatin structure. } \\
\text { histone' }\end{array}$ \\
\hline Putative group 3 LEA protein & 32 & 2 & 1.7701 & 0.0191 & LOC_Os05g46480.1 & $\begin{array}{l}\text { reproduction, post-embryonic } \\
\text { development, embryo development }\end{array}$ \\
\hline
\end{tabular}


Table 1 Differentially expressed proteins in shoot tissues of pokkali w.r.t IR64 (Continued)

\begin{tabular}{|c|c|c|c|c|c|c|}
\hline Protein identity & $\%$ coverage & Peptides & $\begin{array}{l}\text { POK } \\
\text { IR64 }\end{array}$ & pvalue & MSU ID & Protein function \\
\hline $\begin{array}{l}\text { Putative Ras-GTPase-activating } \\
\text { protein binding protein } 1\end{array}$ & 6.5 & 2 & 87.0964 & 0.0182 & LOC_Os02g29480.1 & 'protein.targeting.nucleus' \\
\hline $\begin{array}{l}\text { Coproporphyrinogen III oxidase, } \\
\text { chloroplast }\end{array}$ & 16.8 & 1 & 87.9023 & 0.0189 & LOC_Os04g52130.1 & $\begin{array}{l}\text { 'tetrapyrrole synthesis.coproporphyrinogen } \\
\text { III oxidase' }\end{array}$ \\
\hline $\begin{array}{l}\text { OsAPx6 - Stromal Ascorbate } \\
\text { Peroxidase }\end{array}$ & 25.6 & 5 & 8.091 & 0.0366 & LOC_Os12g07820.1 & 'redox.ascorbate and glutathione.ascorbate' \\
\hline Peptidyl-prolyl cis-trans isomerase & 26.8 & 1 & 99.0832 & 0.0192 & LOC_Os02g52290.1 & 'protein.folding' \\
\hline $\begin{array}{l}\text { Methionyl-tRNA synthetase, } \\
\text { putative }\end{array}$ & 23 & 1 & 87.9023 & 0.0185 & LOC_Os04g23820.1 & 'protein.aa activation' \\
\hline $\begin{array}{l}\text { Dihydroorotate dihydrogenase } \\
\text { protein }\end{array}$ & 9.4 & 1 & 1.0965 & 0.027 & LOC_Os02g50350.1 & $\begin{array}{l}\text { 'nucleotide metabolism.degradation.pyrimidine. } \\
\text { dihydrouracil dehydrogenase' }\end{array}$ \\
\hline Thylakoid lumenal protein & 24.6 & 4 & 1.1482 & 0.0409 & LOC_Os02g42960.1 & Biological process \\
\hline cDNA clone:001-039-F07 & 24.5 & 3 & 2.9648 & 0.0454 & LOC_Os12g02370.2 & 'secondary metabolism.flavonoids.chalcones' \\
\hline Putative uncharacterized protein & 23.8 & 3 & 31.0456 & 0.0009 & LOC_Os01g34700.1 & biological_process/metabolic process \\
\hline Non-specific lipid-transfer protein & 27.1 & 3 & 64.8634 & 0.0186 & LOC_Os11g02369.1 & $\begin{array}{l}\text { LTPL7 - Protease inhibitor/seed storage/LTP } \\
\text { family protein precursor }\end{array}$ \\
\hline EF hand family protein & 27.9 & 3 & 2.0137 & 0.0175 & LOC_Os03g29770.1 & 'signalling.calcium' \\
\hline Os05g0291700 protein & 25.8 & 2 & 2.2491 & 0.0411 & LOC_Os05g22614.4 & metabolic process/biological process \\
\hline ATP synthase subunit alpha & 15.3 & 2 & 1.4997 & 0.0367 & LOC_Os09g08910.1 & $\begin{array}{l}\text { 'mitochondrial electron transport / ATP } \\
\text { synthesis.F1-ATPase' }\end{array}$ \\
\hline High mobility group protein & 17.8 & 2 & 99.0832 & 0.0172 & LOC_Os06g51220.4 & cellular component organization \\
\hline stress responsive protein & 8.3 & 2 & 1.2474 & 0.0481 & LOC_Os03g21040.2 & Biological process \\
\hline phytocyanin-related protein Pn14 & 10.4 & 2 & 87.9023 & 0.0188 & LOC_Os08g17160.1 & 'misc.plastocyanin-like' \\
\hline $\begin{array}{l}\text { Putative uncharacterized protein/ } \\
\text { aminotransferase }\end{array}$ & 3.9 & 2 & 87.9023 & 0.0182 & LOC_Os04g52440.1 & $\begin{array}{l}\text { 'amino acid metabolism.synthesis.central amino } \\
\text { acid metabolism.GABA.GABA transaminase' }\end{array}$ \\
\hline $\begin{array}{l}\text { PREDICTED: DNA-binding } \\
\text { protein MNB1B }\end{array}$ & 43.4 & 3 & 8.0168 & 0.0009 & LOC_Os02g26440.1 & protein metabolic process \\
\hline $\begin{array}{l}\text { xyloglucan endotransglycosylase/ } \\
\text { hydrolase protein } 8\end{array}$ & 15.9 & 2 & 6.5464 & 0.0388 & LOC_Os08g13920.1 & 'cell wall.modification' \\
\hline $\begin{array}{l}\text { ribosomal protein/ } \\
\text { LOC_Os02g33140.1 }\end{array}$ & 20.2 & 1 & 99.0832 & 0.0188 & LOC_Os02g33140.1 & $\begin{array}{l}\text { 'protein.synthesis.ribosomal protein.eukaryotic. } \\
40 S \text { subunit.S14' }\end{array}$ \\
\hline $\begin{array}{l}\text { Putative Photosystem I } \\
\text { reaction center subunit IV }\end{array}$ & 12.8 & 1 & 8.0168 & 0.0191 & LOC_Os07g25430.1 & $\begin{array}{l}\text { 'PS.lightreaction.photosystem I.PSI polypeptide } \\
\text { subunits' }\end{array}$ \\
\hline Actin-1 & 15.9 & 1 & 99.0832 & 0.019 & LOC_Os03g50885.1 & cellular component organization \\
\hline $\begin{array}{l}\text { Putative peptidyl-prolycis-trans } \\
\text { isomerase protein }\end{array}$ & 6.7 & 1 & 1.6904 & 0.0385 & LOC_Os07g37830.1 & 'cell.cycle.peptidylprolyl isomerase' \\
\hline HMG protein & 31.8 & 1 & 87.9023 & 0.0179 & LOC_Os04g47690.2 & Biological process (DNA binding) \\
\hline Putative uncharacterized protein & 5.3 & 1 & 9.3756 & 0.0384 & LOC_Os12g15470.2 & 'protein.degradation.serine protease' \\
\hline $\begin{array}{l}\text { ferredoxin-dependent glutamate } \\
\text { synthase, }\end{array}$ & 2.1 & 1 & 64.2688 & 0.0187 & LOC_Os07g46460.1 & $\begin{array}{l}\text { 'N-metabolism.ammonia metabolism. } \\
\text { glutamate synthase' }\end{array}$ \\
\hline Os07g0585000 protein & 8.1 & 1 & 87.9023 & 0.0183 & LOC_Os07g39620.2 & 'stress.abiotic.cold' \\
\hline $\begin{array}{l}\text { putative CR9/Light-regulated } \\
\text { protein }\end{array}$ & 22.7 & 1 & 99.0832 & 0.0182 & LOC_Os01g01340.1 & vacuolar transport \\
\hline GDP-mannose 3,5-epimerase 1 & 5.6 & 1 & 99.0832 & 0.0187 & LOC_Os10g28200.1 & $\begin{array}{l}\text { 'redox.ascorbate and glutathione.ascorbate. } \\
\text { GME' }\end{array}$ \\
\hline Lipid transfer protein-like & 4.8 & 1 & 99.0832 & 0.0181 & LOC_Os07g09970.1 & $\begin{array}{l}\text { 'misc.protease inhibitor/seed storage/lipid } \\
\text { transfer protein (LTP) family protein' }\end{array}$ \\
\hline TA9 protein-like & 1.5 & 1 & 99.0832 & 0.0181 & LOC_Os01g47430.2 & DUF1296 domain containing protein \\
\hline Os01g0763650 protein & 7.9 & 1 & 99.0832 & 0.0188 & LOC_Os01g0763700 & lipid metabolic process \\
\hline
\end{tabular}


Table 1 Differentially expressed proteins in shoot tissues of pokkali w.r.t IR64 (Continued)

\begin{tabular}{|c|c|c|c|c|c|c|}
\hline Protein identity & $\%$ coverage & Peptides & $\begin{array}{l}\text { POK } \\
\text { IR64 }\end{array}$ & pvalue & MSU ID & Protein function \\
\hline dirigent protein 22 & 6.3 & 1 & 99.0832 & 0.0189 & LOC_Os11g07670.1 & 'stress.biotic.PR-proteins' \\
\hline KE2 family protein & 5.4 & 1 & 99.0832 & 0.0186 & LOC_Os12g30060.2 & protein metabolic process \\
\hline $\begin{array}{l}\text { Glucan endo-1,3-beta- } \\
\text { glucosidase } 5\end{array}$ & 5.5 & 1 & 99.0832 & 0.0198 & LOC_Os11g36940.1 & $\begin{array}{l}\text { 'misc.beta 1,3 glucan hydrolases.glucan endo- } \\
\text { 1,3-beta-glucosidase' }\end{array}$ \\
\hline Os08g0459300 protein & 5.8 & 1 & 85.5067 & 0.019 & LOC_Os08g35710.1 & $\begin{array}{l}\text { 'PS.lightreaction.other electron carrier } \\
\text { (ox/red).ferredoxin' }\end{array}$ \\
\hline $\begin{array}{l}\text { LOC_Os03g45340.1/hsp20/alpha } \\
\text { crystallin family protein }\end{array}$ & 15.6 & 1 & 25.3513 & 0.019 & LOC_Os03g45340.1 & response to abiotic stimulus \\
\hline $\begin{array}{l}\text { Os08g0530200/Putative } \\
\text { ribosomal protein L17 }\end{array}$ & 15.8 & 2 & 6.3096 & 0.0441 & LOC_Os08g41810.1 & $\begin{array}{l}\text { 'protein.synthesis.ribosomal protein.eukaryotic. } \\
605 \text { subunit.L17' }\end{array}$ \\
\hline HIPL1 protein, putative & 6.1 & 1 & 15.1356 & 0.0188 & LOC_Os12g44230.1 & 'cell.organisation' \\
\hline \multicolumn{7}{|l|}{ (B) Control Down } \\
\hline T-complex protein, putative, & 48.3 & 29 & 0.1585 & 0 & LOC_Os12g17910.1 & 'protein.folding' \\
\hline ATP synthase subunit beta & 46.4 & 18 & 0.4786 & 0.026 & LOC_Os10g21266.1 & $\begin{array}{l}\text { 'mitochondrial electron transport / ATP } \\
\text { synthesis.F1-ATPase' }\end{array}$ \\
\hline Putative transketolase & 28 & 10 & 0.0692 & 0.0002 & LOC_Os06g04270.1 & 'PS.calvin cycle.transketolase' \\
\hline Dehydroascorbate reductase & 65.3 & 9 & 0.0929 & 0.0485 & LOC_Os05g02530.1 & 'redox.ascorbate and glutathione.ascorbate' \\
\hline Peptidyl-prolyl cis-trans isomerase & 61.1 & 10 & 0.092 & 0.0103 & LOC_Os02g02890.1 & 'cell.cycle.peptidylprolyl isomerase' \\
\hline Glyoxalase & 26.5 & 9 & 0.1472 & 0.0436 & LOC_Os08g09250.2 & $\begin{array}{l}\text { amino acid metabolism.degradation. } \\
\text { aspartate family.threonine' }\end{array}$ \\
\hline peroxiredoxin, putative & 35.6 & 4 & 0.038 & 0.0465 & LOC_Os02g09940.1 & 'redox.peroxiredoxin' \\
\hline T-complex protein, putative & 14.3 & 4 & 0.3373 & 0.0418 & LOC_Os06g02380.2 & 'protein.folding' \\
\hline Carbonic anhydrase & 32.7 & 5 & 0.5395 & 0.0208 & LOC_Os01g45274.1 & $\begin{array}{l}\text { 'TCA / org. Transformation.carbonic } \\
\text { anhydrases' }\end{array}$ \\
\hline glycine-rich protein 2 , putative & 47.2 & 3 & 0.138 & 0.014 & LOC_Os01g36570.1 & 'stress.abiotic.cold' \\
\hline $\begin{array}{l}\text { plasminogen activator inhibitor } \\
1 \text { RNA-binding protein }\end{array}$ & 30.5 & 4 & 0.5445 & 0.0414 & LOC_Os05g45660.2 & 'RNA.RNA binding' \\
\hline $\begin{array}{l}\text { NAD dependent epimerase/ } \\
\text { dehydratase }\end{array}$ & 8.4 & 1 & 0.278 & 0.0448 & LOC_Os07g11110.1 & 'RNA.regulation of transcription.unclassified' \\
\hline 60 kDa chaperonin alpha subunit & 39.8 & 17 & 0.0871 & 0.0445 & LOC_Os11g47970.1 & AAA-type ATPase family protein \\
\hline $\begin{array}{l}\text { Ribulose bisphosphate } \\
\text { carboxylase small chain }\end{array}$ & 57.7 & 14 & 0.1169 & 0.0039 & LOC_Os12g17600.1 & $\begin{array}{l}\text { ribulose bisphosphate carboxylase small } \\
\text { chain }\end{array}$ \\
\hline Putative uncharacterized protein & 34.9 & 3 & 0.1614 & 0.0324 & LOC_Os03g08800.1 & CutA, chloroplast precursor, putative \\
\hline Protein CutA, chloroplast, & 20.4 & 1 & 0.9204 & 0.043 & LOC_Os04g50110.1 & RNA recognition motif containing protein, \\
\hline $\begin{array}{l}\text { Putative uncharacterized } \\
\text { protein }\end{array}$ & 8.3 & 2 & 0.0111 & 0.0444 & LOC_Os03g20630.2 & histidine triad family protein, \\
\hline \multicolumn{7}{|l|}{ (C) Stress UP } \\
\hline $\begin{array}{l}\text { Oxygen-evolving enhancer } \\
\text { protein } 1 \text {, chloroplast }\end{array}$ & 58 & 43 & 15.7036 & 0.0028 & LOC_Os01g31690.1 & $\begin{array}{l}\text { PS.lightreaction.photosystem II.PSII } \\
\text { polypeptide subunits' }\end{array}$ \\
\hline $\begin{array}{l}\text { Ribulose bisphosphate } \\
\text { carboxylase large chain } 1\end{array}$ & 53.5 & 41 & 5.4954 & 0.0126 & LOC_Os10g21268.1 & 'PS.calvin cycle.rubisco large subunit' \\
\hline PsbP & 71.3 & 32 & 19.0546 & 0.0129 & LOC_Os07g04840.1 & $\begin{array}{l}\text { PS.lightreaction.photosystem II.PSII } \\
\text { polypeptide subunits' }\end{array}$ \\
\hline $\begin{array}{l}\text { Putative inorganic } \\
\text { pyrophosphatase }\end{array}$ & 65.4 & 22 & 4.7424 & 0.0126 & LOC_Os02g52940.2 & $\begin{array}{l}\text { 'nucleotide metabolism.phosphotransfer } \\
\text { and pyrophosphatases.misc' }\end{array}$ \\
\hline Catalase & 36.2 & 16 & 3.2509 & 0.0041 & LOC_Os02g02400.1 & 'redox.dismutases and catalases' \\
\hline $\begin{array}{l}\text { protein|ribosome recycling } \\
\text { factor, putative }\end{array}$ & 49.6 & 18 & 3.1623 & 0.0001 & LOC_Os07g38300.1 & 'cell.division' \\
\hline Phosphoribulokinase & 45.2 & 16 & 2.5119 & 0.0214 & LOC_Os02g47020.1 & 'PS.calvin cycle.PRK' \\
\hline
\end{tabular}


Table 1 Differentially expressed proteins in shoot tissues of pokkali w.r.t IR64 (Continued)

\begin{tabular}{|c|c|c|c|c|c|c|}
\hline Protein identity & $\%$ coverage & Peptides & $\begin{array}{l}\text { POK } \\
\text { IR64 }\end{array}$ & pvalue & MSU ID & Protein function \\
\hline $\begin{array}{l}\text { protein|salt stress root } \\
\text { protein RS1 }\end{array}$ & 71.6 & 13 & 7.5858 & 0.0005 & LOC_Os01g13210.2 & 'stress.abiotic.drought/salt' \\
\hline Carbonic anhydrase & 53.3 & 16 & 8.1658 & 0.0016 & LOC_Os01g45274.1 & $\begin{array}{l}\text { 'TCA / org. Transformation.carbonic } \\
\text { anhydrases' }\end{array}$ \\
\hline $\begin{array}{l}\text { RNA recognition motif } \\
\text { containing protein }\end{array}$ & 49 & 12 & 5.4954 & 0.002 & LOC_Os09g10760.1 & 'RNA.RNA binding' \\
\hline ABA/WDS induced protein, & 58 & 10 & 4.8306 & 0.0302 & LOC_Os11g06720.1 & abscisic stress-ripening \\
\hline protein|expressed protein & 60.6 & 8 & 1.9409 & 0.0023 & LOC_Os10g18340.2 & 'not assigned.unknown' \\
\hline $\begin{array}{l}30 \text { ribosomal protein } \mathrm{S1} \text {, } \\
\text { chloroplast }\end{array}$ & 23.7 & 6 & 2.0893 & 0.0321 & LOC_Os03g20100.1 & $\begin{array}{l}\text { 'protein.synthesis.ribosomal } \\
\text { protein.prokaryotic.unknown } \\
\text { organellar.30S subunit.S1' }\end{array}$ \\
\hline $\begin{array}{l}30 \text { S ribosomal protein } \mathrm{S} 31 \text {, } \\
\text { chloroplast precursor, }\end{array}$ & 37.3 & 5 & 3.1046 & 0.001 & LOC_Os05g09400.3 & translation \\
\hline Putative group 3 LEA protein & 31.5 & 3 & 5.445 & 0.001 & LOC_Os05g46480.1 & $\begin{array}{l}\text { reproduction, post-embryonic development, } \\
\text { embryo development }\end{array}$ \\
\hline Ankyrin repeat domain protein 2 & 15.1 & 3 & 1.5136 & 0.0012 & LOC_Os03g63480.1 & $\begin{array}{l}\text { 'RNA.regulation of transcription.AtSR } \\
\text { Transcription Factor family' }\end{array}$ \\
\hline $\begin{array}{l}\text { protein|OsCML7 - Calmodulin- } \\
\text { related calcium sensor protein }\end{array}$ & 32.4 & 3 & 1.6596 & 0.0248 & LOC_Os08g02420.1 & 'signalling.calcium' \\
\hline Class III peroxidase 125 & 13.1 & 3 & 6.2517 & 0.0012 & LOC_Os10g02040.1 & 'misc.peroxidases' \\
\hline $\begin{array}{l}\text { linker histone } \mathrm{H} 1 \text { and } \mathrm{H} 5 \\
\text { family protein }\end{array}$ & 20.2 & 1 & 52.9663 & 0.0181 & LOC_Os08g33190.1 & 'DNA.synthesis/chromatin structure.histone' \\
\hline Lipid transfer protein-like & 9.5 & 2 & 83.1764 & 0.0179 & LOC_Os08g42040.1 & 'lipid metabolism.lipid transfer proteins etc' \\
\hline $\begin{array}{l}\text { 1,2-dihydroxy-3-keto-5- } \\
\text { methylthiopentene dioxygenase } \\
\text { protein }\end{array}$ & 26.3 & 1 & 1.028 & 0.0176 & LOC_Os03g06620.1 & 'metal handling.regulation' \\
\hline $\begin{array}{l}\text { oxygen evolving enhancer } \\
\text { protein } 3\end{array}$ & 66.8 & 47 & 11.1686 & 0.01 & LOC_Os07g36080.1 & $\begin{array}{l}\text { 'PS.lightreaction.photosystem II.PSII } \\
\text { polypeptide subunits' }\end{array}$ \\
\hline $\begin{array}{l}\text { Ribulose bisphosphate } \\
\text { carboxylase/oxygenase activase, }\end{array}$ & 57.2 & 38 & 3.4995 & 0.0003 & LOC_Os11g47970.1 & 'PS.calvin cycle.rubisco interacting' \\
\hline $\begin{array}{l}\text { ferredoxin-dependent } \\
\text { glutamate synthase, }\end{array}$ & 13 & 9 & 2.6546 & 0.0018 & LOC_Os07g46460.1 & $\begin{array}{l}\text { 'N-metabolism.ammonia metabolism. } \\
\text { glutamate synthase' }\end{array}$ \\
\hline Putative uncharacterized protein & 40.5 & 9 & 9.3756 & 0.0202 & XP_015634836.1 & $\begin{array}{l}\text { probable peroxisomal membrane protein } \\
\text { PEX13 }\end{array}$ \\
\hline $\begin{array}{l}\text { Os01g0326000 protein/ } \\
\text { peroxidase } 1\end{array}$ & 19.9 & 5 & 2.0137 & 0.0473 & LOC_Os01g22230.1 & 'misc.peroxidases' \\
\hline $\begin{array}{l}\text { CDGSH iron-sulfur domain- } \\
\text { containing protein NEET }\end{array}$ & 52.3 & 4 & 10.3753 & 0.0159 & LOC_Os07g28400.1 & biological_process \\
\hline Os04g0445200 protein & 56.5 & 3 & 3.4995 & 0.0045 & LOC_Os04g36760.1 & NO \\
\hline Q8LQN2|Q8LQN2_ORYSJ & 24.6 & 5 & 1.3932 & 0.0463 & LOC_Os01g57570.1 & $\begin{array}{l}\text { NADPH-dependent FMN reductase } \\
\text { domain containing protein }\end{array}$ \\
\hline $\begin{array}{l}\text { BBTI7 - Bowman-Birk type bran } \\
\text { trypsin inhibitor precursor }\end{array}$ & 15.1 & 2 & 2.2491 & 0.0023 & LOC_Os01g03390.1 & $\begin{array}{l}\text { BBTI7 - Bowman-Birk type bran trypsin } \\
\text { inhibitor precursor }\end{array}$ \\
\hline $\begin{array}{l}\text { OSJNBa0086006.22 protein/31 } \\
\text { kDa ribonucleoprotein }\end{array}$ & 10.7 & 3 & 1.9588 & 0.0013 & LOC_Os04g50110.1 & 'RNA.RNA binding' \\
\hline $\begin{array}{l}\text { Os06g0671900 protein/ } \\
\text { Q0DA75|Q0DA75_ORYSJ }\end{array}$ & 13.6 & 2 & 1.2246 & 0.0378 & LOC_Os06g46000.1 & tubulin/FtsZ domain containing protein \\
\hline $\begin{array}{l}\text { LTPL52 - Protease inhibitor/ } \\
\text { seed storage }\end{array}$ & 21.8 & 2 & 2.3768 & 0.0009 & LOC_Os03g26820.1 & transport \\
\hline Putative SHOOT1 protein & 18.8 & 1 & 5.2966 & 0.0319 & LOC_Os07g07540.1 & response to stress \\
\hline Glutamate dehydrogenase & 7.8 & 1 & 99.0832 & 0.019 & LOC_Os03g58040.2 & $\begin{array}{l}\text { 'N-metabolism.N-degradation.glutamate } \\
\text { dehydrogenase' }\end{array}$ \\
\hline
\end{tabular}


Table 1 Differentially expressed proteins in shoot tissues of pokkali w.r.t IR64 (Continued)

\begin{tabular}{|c|c|c|c|c|c|c|}
\hline Protein identity & $\%$ coverage & Peptides & $\begin{array}{l}\text { POK } \\
\text { IR64 }\end{array}$ & pvalue & MSU ID & Protein function \\
\hline Alpha-tubulin & 9.1 & 1 & 42.0727 & 0.0184 & LOC_Os11g14220.1 & $\begin{array}{l}\text { cell.organisation'/response to abiotic } \\
\text { stimulus }\end{array}$ \\
\hline \multicolumn{7}{|l|}{ (D) Stress Down } \\
\hline enolase, putative & 37.1 & 9 & 0.4742 & 0.0065 & LOC_Os10g08550.1 & 'glycolysis.cytosolic branch.enolase' \\
\hline $\begin{array}{l}\text { ubiquitin fusion protein, } \\
\text { putative }\end{array}$ & 61.2 & 13 & 0.3311 & 0.0313 & LOC_Os09g39500.1 & 'protein.degradation.ubiquitin.ubiquitin' \\
\hline Glyoxalase & 33.7 & 10 & 0.2754 & 0.0121 & LOC_Os08g09250.2 & $\begin{array}{l}\text { amino acid metabolism.degradation.aspartate } \\
\text { family.threonine' }\end{array}$ \\
\hline $\begin{array}{l}\text { Glyceraldehyde-3-phosphate } \\
\text { dehydrogenase }\end{array}$ & 37.1 & 10 & 0.3221 & 0.0005 & LOC_Os04g40950.1 & $\begin{array}{l}\text { 'glycolysis.cytosolic branch.glyceraldehyde } \\
\text { 3-phosphate dehydrogenase (GAP-DH)' }\end{array}$ \\
\hline Malate dehydrogenase & 37.4 & 7 & 0.3048 & 0.0326 & LOC_Os10g33800.1 & $\begin{array}{l}\text { 'TCA / org. Transformation.other organic } \\
\text { acid transformaitons.cyt MDH' }\end{array}$ \\
\hline Nucleoside diphosphate kinase & 48.3 & 5 & 0.2051 & 0.0283 & LOC_Os10g41410.2 & $\begin{array}{l}\text { 'nucleotide metabolism.phosphotransfer } \\
\text { and pyrophosphatases.nucleoside } \\
\text { diphosphate kinase' }\end{array}$ \\
\hline Stress responsive protein & 20.3 & 3 & 0.1644 & 0.0276 & LOC_Os01g01450.1 & Stress responsive protein \\
\hline $\begin{array}{l}\text { L11 domain containing } \\
\text { ribosomal protein }\end{array}$ & 31.3 & 3 & 0.0316 & 0.0081 & LOC_Os02g47140.1 & $\begin{array}{l}\text { 'protein.synthesis.ribosomal } \\
\text { protein.eukaryotic.60S subunit.L12' }\end{array}$ \\
\hline Class III peroxidase 65 & 21.6 & 6 & 0.1905 & 0.0181 & LOC_Os05g04380.1 & 'misc.peroxidases' \\
\hline RNase S-like protein & 30.2 & 3 & 0.0119 & 0.0067 & LOC_Os09g36680.1 & 'RNA.processing.ribonucleases' \\
\hline Phenylalanine ammonia-lyase & 13 & 3 & 0.7727 & 0.0162 & LOC_Os02g41630.2 & $\begin{array}{l}\text { 'secondary metabolism.phenylpropanoids. } \\
\text { lignin biosynthesis.PAL' }\end{array}$ \\
\hline Probable aldo-keto reductase 2 & 19.1 & 2 & 0.0938 & 0.016 & LOC_Os04g26910.1 & $\begin{array}{l}\text { 'hormone metabolism.auxin.induced- } \\
\text { regulated-responsive-activated' }\end{array}$ \\
\hline ranBP1 domain containing protein & 5.7 & 2 & 0.0316 & 0.0075 & LOC_Os05g28190.1 & 'signalling.G-proteins' \\
\hline $\begin{array}{l}\text { Putative Ras-GTPase-activating } \\
\text { protein binding protein } 1\end{array}$ & 13.1 & 1 & 0.2014 & 0.0451 & LOC_Os02g29480.1 & 'protein.targeting.nucleus' \\
\hline Fructose-bisphosphate aldolase & 30.2 & 8 & 0.0296 & 0.0041 & LOC_Os01g67860.1 & 'PS.calvin cycle.aldolase' \\
\hline $\begin{array}{l}\text { enoyl-acyl-carrier-protein } \\
\text { reductase NADH }\end{array}$ & 22.6 & 5 & 0.6982 & 0.0133 & LOC_Os08g23810.1 & $\begin{array}{l}\text { 'lipid metabolism.FA synthesis and FA } \\
\text { elongation.enoyl ACP reductase' }\end{array}$ \\
\hline dehydrogenase, putative & 27.2 & 3 & 0.912 & 0.0169 & LOC_Os08g29170.1 & 'misc.oxidases - copper, flavone etc.' \\
\hline SOR/SNZ family protein & 22.7 & 4 & 0.6138 & 0.0257 & LOC_Os10g01080.1 & 'Co-factor and vitamine metabolism' \\
\hline ketol-acid reductoisomerase & 10.3 & 3 & 0.9376 & 0.0359 & LOC_Os05g49800.1 & $\begin{array}{l}\text { 'amino acid metabolism.synthesis.branched } \\
\text { chain group.common' }\end{array}$ \\
\hline $\begin{array}{l}\text { NAD dependent epimerase/ } \\
\text { dehydratase family }\end{array}$ & 10.6 & 3 & 0.0283 & 0.0056 & LOC_Os03g16980.1 & 'cell wall.precursor synthesis.UXS' \\
\hline $\begin{array}{l}\text { erythronate-4-phosphate } \\
\text { dehydrogenase domain } \\
\text { containing }\end{array}$ & 22.6 & 3 & 0.053 & 0.0119 & LOC_Os06g29180.1 & 'C1-metabolism' \\
\hline transaldolase & 12.3 & 2 & 0.1019 & 0.0146 & LOC_Os01g70170.1 & 'OPP.non-reductive PP.transaldolase' \\
\hline peptidase, $\mathrm{T} 1$ family & 11.5 & 2 & 0.0313 & 0.04 & LOC_Os02g42320.2 & 'protein.degradation.ubiquitin.proteasom' \\
\hline actin, putative & 21 & 2 & 0.4966 & 0.048 & LOC_Os11g06390.4 & 'cell.organisation' \\
\hline $\begin{array}{l}\text { RNA recognition motif } \\
\text { containing protein }\end{array}$ & 41.3 & 3 & 0.5058 & 0.0222 & LOC_Os01g68790.2 & 'RNA.RNA binding' \\
\hline osmotin, putative & 11.6 & 2 & 0.5012 & 0.0451 & LOC_Os12g38170.1 & 'stress.abiotic' \\
\hline $\begin{array}{l}\mathrm{NADPH} \text {-dependent FMN } \\
\text { reductase domain containing } \\
\text { protein }\end{array}$ & 19.2 & 3 & 0.0121 & 0.0492 & LOC_Os08g04460.1 & $\begin{array}{l}\text { 'lipid metabolism."exotics" (steroids, squalene } \\
\text { etc)' }\end{array}$ \\
\hline
\end{tabular}




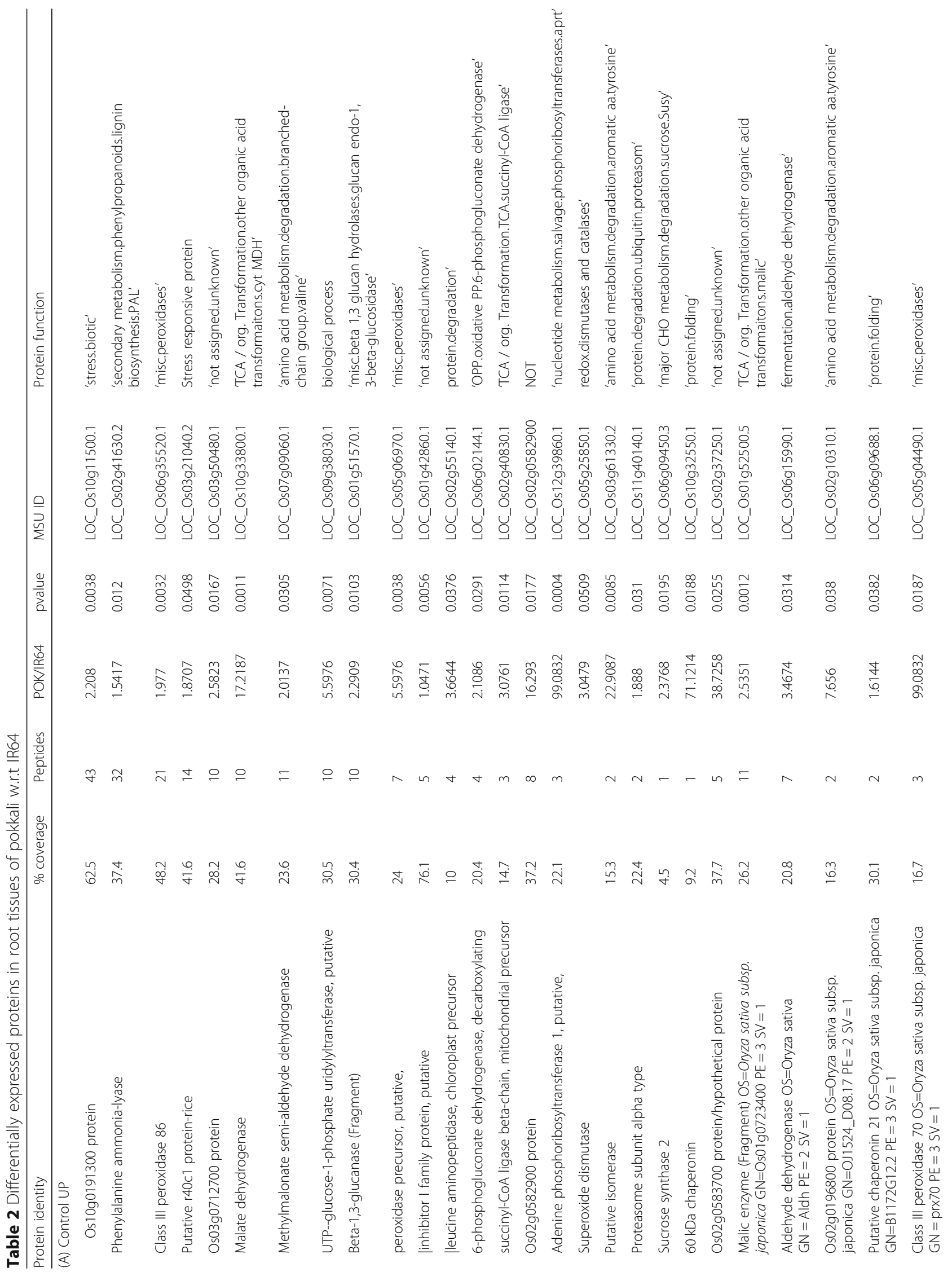




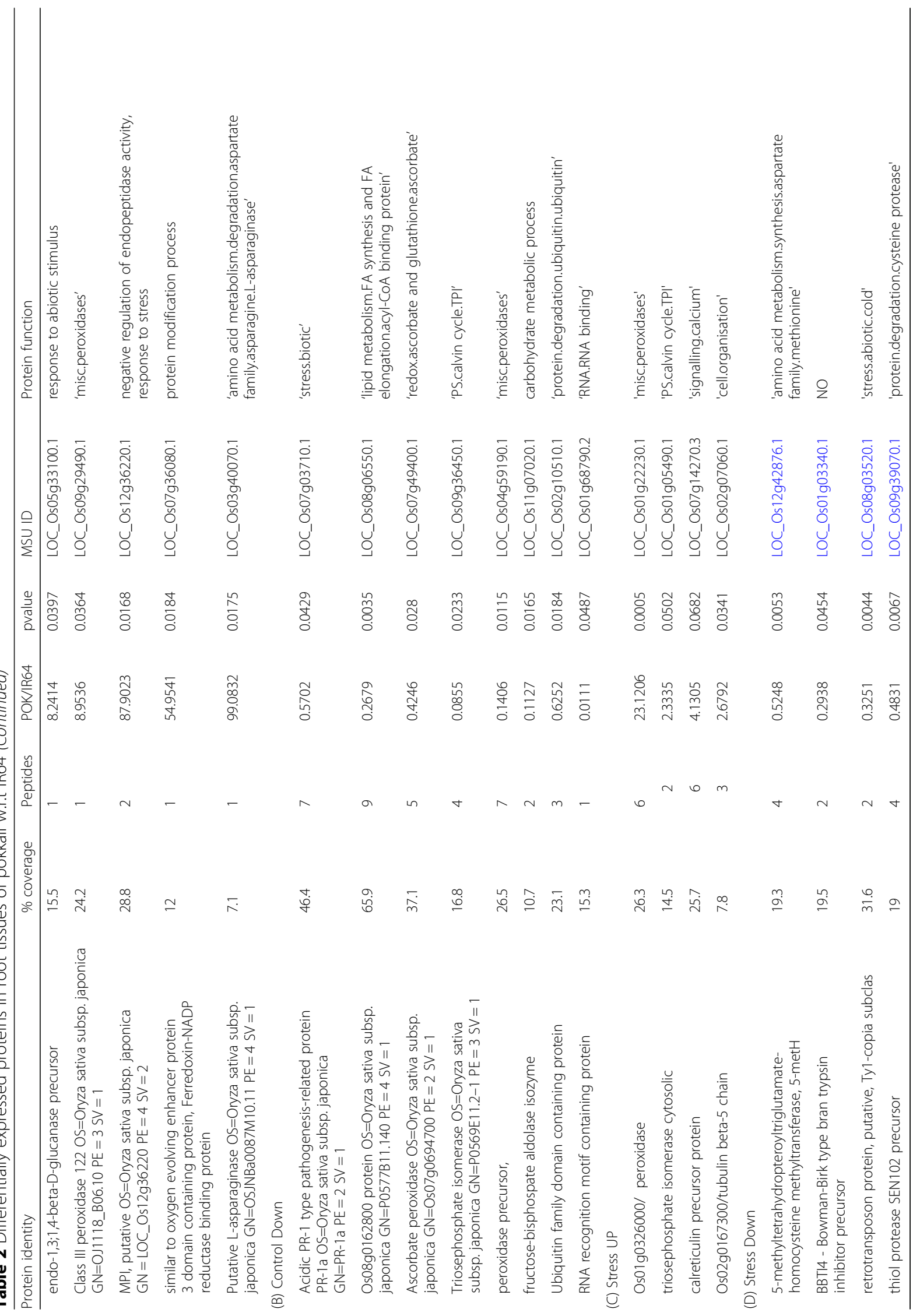




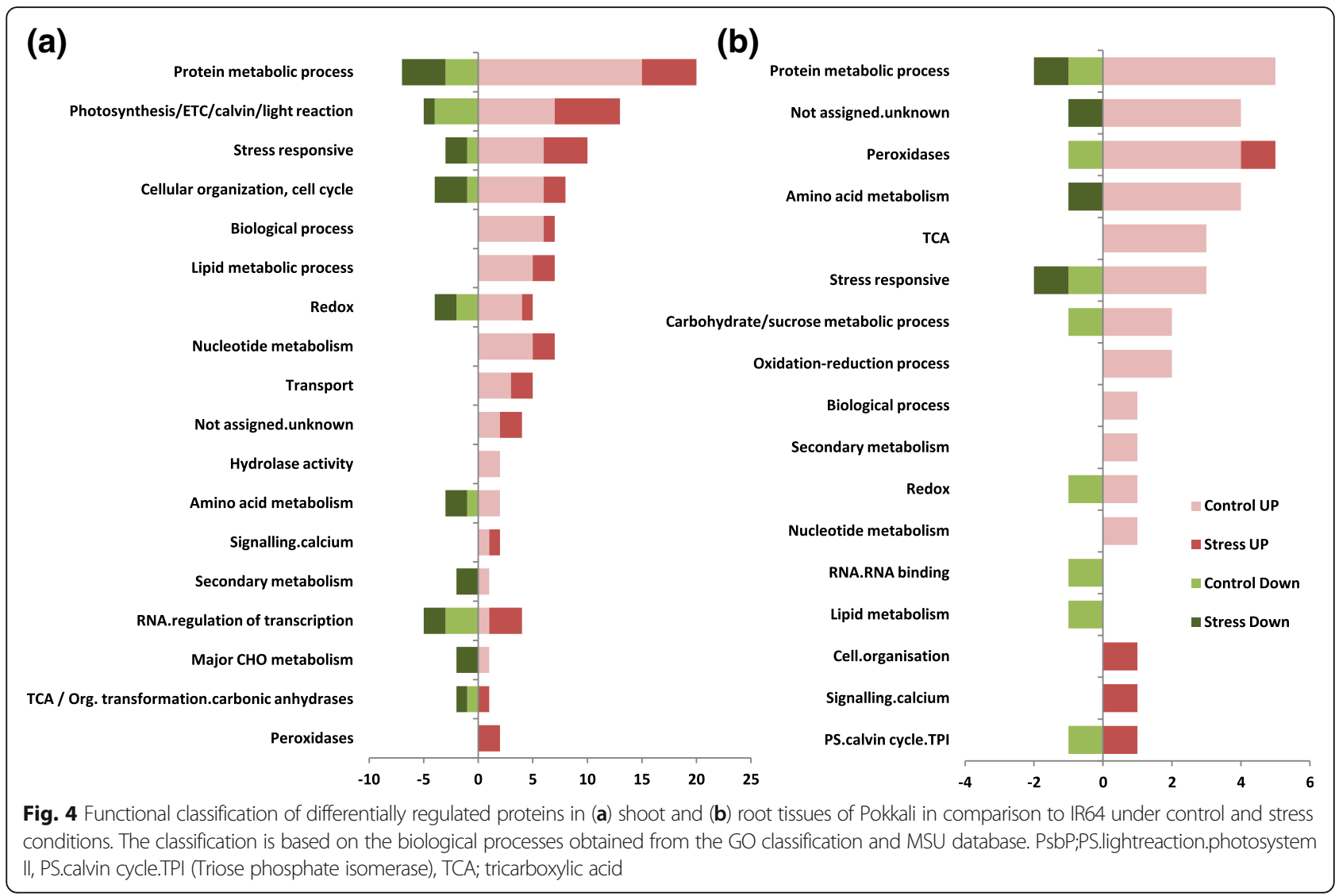

involved in stress response and adaptation in comparison to IR64. However, it should be noted that there are other stress-responsive proteins in the Pokkali proteome as well, which though are more abundant than in IR64 but have not been considered here (present in higher amount with a little change in their abundance) and hence, need low increment in their abundance for appropriately performing their functions.

\section{Hierarchical clustering of differentially expressed proteins in Pokkali vs IR64}

Hierarchical clustering analysis was performed to understand the pattern of protein expression in Pokkali vs IR64 under control and stress conditions. For this, proteins common between control and stressed proteome of Pokkali and IR64 were taken for analysis. Twenty three proteins grouped as cluster one, were found to be highly expressed in Pokkali under control conditions in comparison to IR64 but under salinity stress, their expression pattern reversed where these proteins exhibited higher expression levels in IR64 than Pokkali. These proteins included four prolyl peptidyl cis-trans isomerases (PPiases), a superoxide dismutase protein, a metallo-beta lactamase protein, DnaK protein, OsAPX6, coproporphyrinogen oxidase and Calvin cycle protein CP12 (Fig. 5a). However, in this cluster, there were few proteins which were though highly expressed under control conditions in Pokkali but little change under stress conditions such as peptidyl-prolyl cis-trans isomerases (Os02g52290.1 and Os06g45340.1), peptidyl-prolyl cis-trans isomerase FKBP type, elongation factor and DnaK family protein (Os12g14070.1 and Os02g53420.1) (Listed in Additional file 4: Table S2). Further, few proteins grouped in cluster 2, such as, OsCML7 and a histone protein, exhibited a minimal change in their expression pattern under stress when compared to the differential control proteome of Pokkali. The third type of cluster was composed of proteins which exhibited low expression in Pokkali viz. IR64 under non-stress conditions but showed a significant increase in Pokkali under stress. This category included various proteins such as, ankyrin repeat domain protein 2 , catalase, 30 S ribosomal proteins, thylakoid luminal protein, LEA protein, ribulose bisphosphate carboxylase and phosphoribulokinase (Cluster 3; Fig. 5a). Cluster 4, which comprised of proteins with increased expression in Pokkali with respect to IR64 under both control and stress conditions were also observed. This group comprised proteins such as oxygen evolving enhancer proteins (OEE), thioredoxin, Class III peroxidase, and lipid transfer proteins (Fig. 5a).

Similarly, the differentially expressed proteins in root proteome of Pokkali were also found to be clustered into various groups (Fig. 5b). A number of proteins like malate dehydrogenase, peroxidase, $60 \mathrm{kDa}$ chaperonin protein, 


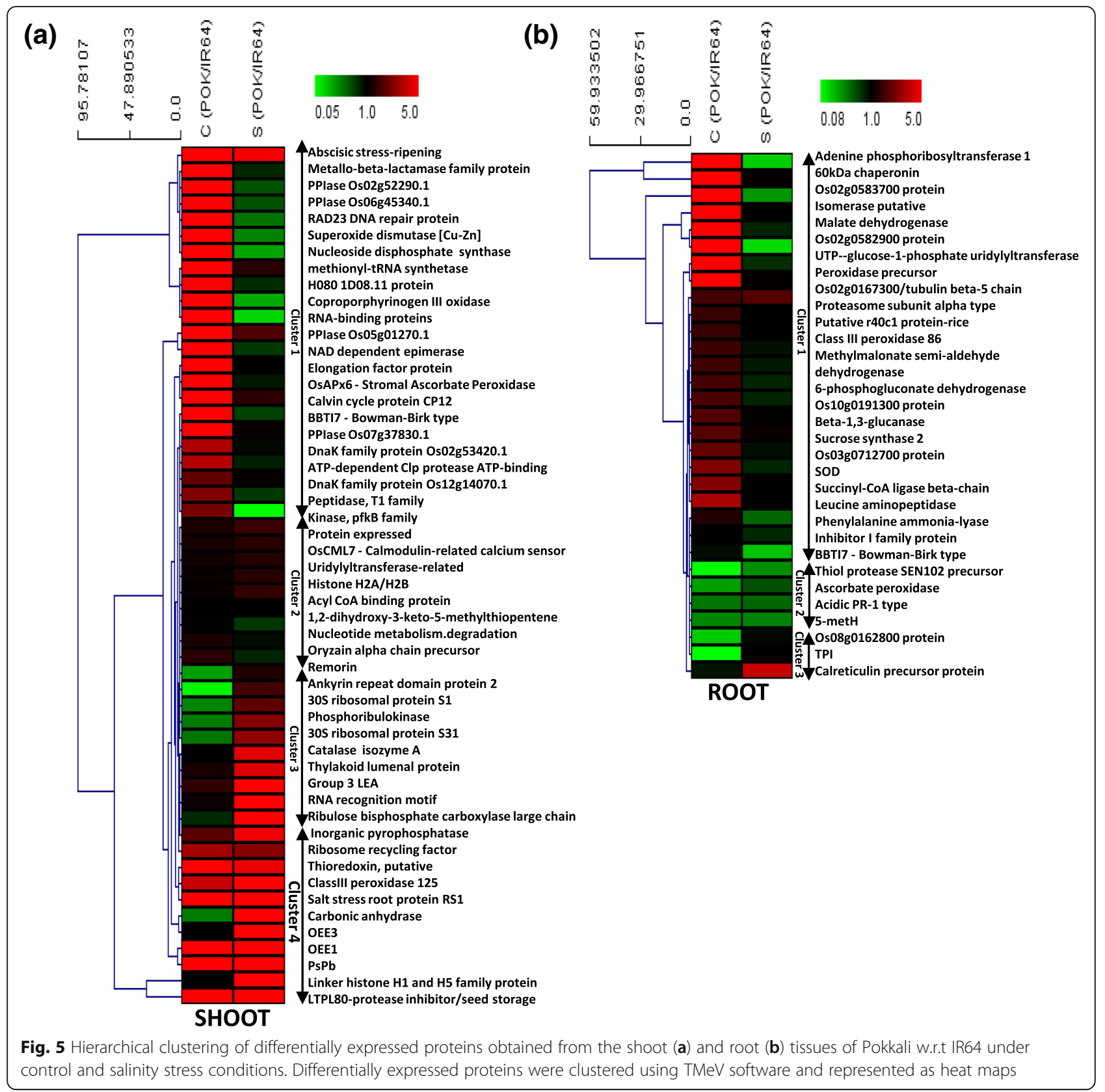

adenine phosphoribosyltransferase 1 (APRT1), methylmalonate semi-aldehyde (MMSDH), 6-phosphogluconate dehydrogenase (6PGDH), Succinyl-CoA ligase (SCoAL), and leucine aminopeptidase were found to be highly abundant under non-stress conditions in Pokkali then to IR64 but under stress, levels of these proteins either increased in IR64 with respect to Pokkali or decreased with respect to their control levels in Pokkali (Cluster 1; Fig. 5b). Another group comprised of proteins whose expression levels remained low in control as well as in stress conditions in Pokkali with respect to IR64 and included proteins such as, thiol protease, acidic PR-1 type pathogenesis related protein, and sucrose synthase (Cluster 2; Fig. 5b). The third group comprised of proteins like calreticulin and triose phosphate isomerase which were either low in expression or exhibited only marginally higher expression in Pokkali with respect to IR64 under control conditions but their expression ratio (Pokkali vs. IR64) increased under stress conditions (Cluster 3; Fig. 5b).

Transcript abundance of selected genes using qRT-PCR In order to investigate the correlation between the transcript and protein profiles of differentially expressed proteins, we measured the transcript levels of few selected proteins under both control and stress conditions in Pokkali and IR64. Twelve proteins obtained from shoot proteome and four 
from root proteome were selected for this analysis. Proteins selected from shoot proteome primarily belonged to three major functional categories viz. protein metabolic process, photosynthesis and stress response as shown in Fig. 4a. Proteins such as, oxygen-evolving enhancer protein (OEE) 1, (PsbP), lipid transfer protein (LTP) - Protease inhibitor/seed storage, salt stress root protein RS1 and Ribosomal L9 (Rib L9) exhibited enhanced transcript levels under control as well as stress conditions in Pokkali with respect to IR64, much like their protein levels (Fig. 6 a-l). Other proteins such as, Calvin cycle protein CP12 (chloroplast protein), oxygen-evolving enhancer protein (OEE3) and ribosomal protein (RibP), exhibited an increase in their transcript levels in Pokkali under control conditions in correlation with their protein levels but under stress, though relative expression levels of these proteins remained higher in Pokkali vs. IR64, their transcript profile indicated that transcript accumulation was more in IR64 than Pokkali at $2 \mathrm{~h}$ of stress (Fig. 6 $\mathrm{d}, \mathrm{g}, \mathrm{j})$. Ascorbate peroxidase (APX) was found to be the only protein whose transcript and protein levels showed positive correlation in their expression pattern at both control and stress conditions. Further, glutamate dehydrogenase $(\mathrm{GluDH})$ protein levels though were not detectable under control conditions but transcript profile showed higher accumulation in Pokkali under control conditions. Under stress, both protein and transcript abundance of GluDH was more in Pokkali viz. IR64. Another protein, ribosomal protein (Rib L9) was is detected only under control conditions at protein level but transcripts accumulated under both control and stress conditions in Pokkali. A carbonic anhydrase (CA), was found to show increased transcript accumulation under both control as well as stress conditions in Pokkali with respect to IR64 but by contrast, its protein levels were less in Pokkali than IR64 under control conditions (Fig. 6 a-l).

Four proteins including, two triose phosphate isomerases (TPI), a sucrose synthase (Susy) and a peroxidase, obtained from the root proteome analysis were also studied for their transcript alterations in Pokkali and IR64. The transcript accumulation pattern of TPI matched its protein expression profiles under both control and stress conditions, however sucrose synthase exhibited an opposite transcript accumulation pattern in comparison to its protein profile under control conditions in Pokkali. Under salinity stress, however both transcript and protein levels of sucrose synthase were found to increase in Pokkali in comparison to IR64 (Fig. $6 \mathrm{~m}$-p). Another candidate, peroxidase, showed an increase in transcript levels under both control and stress

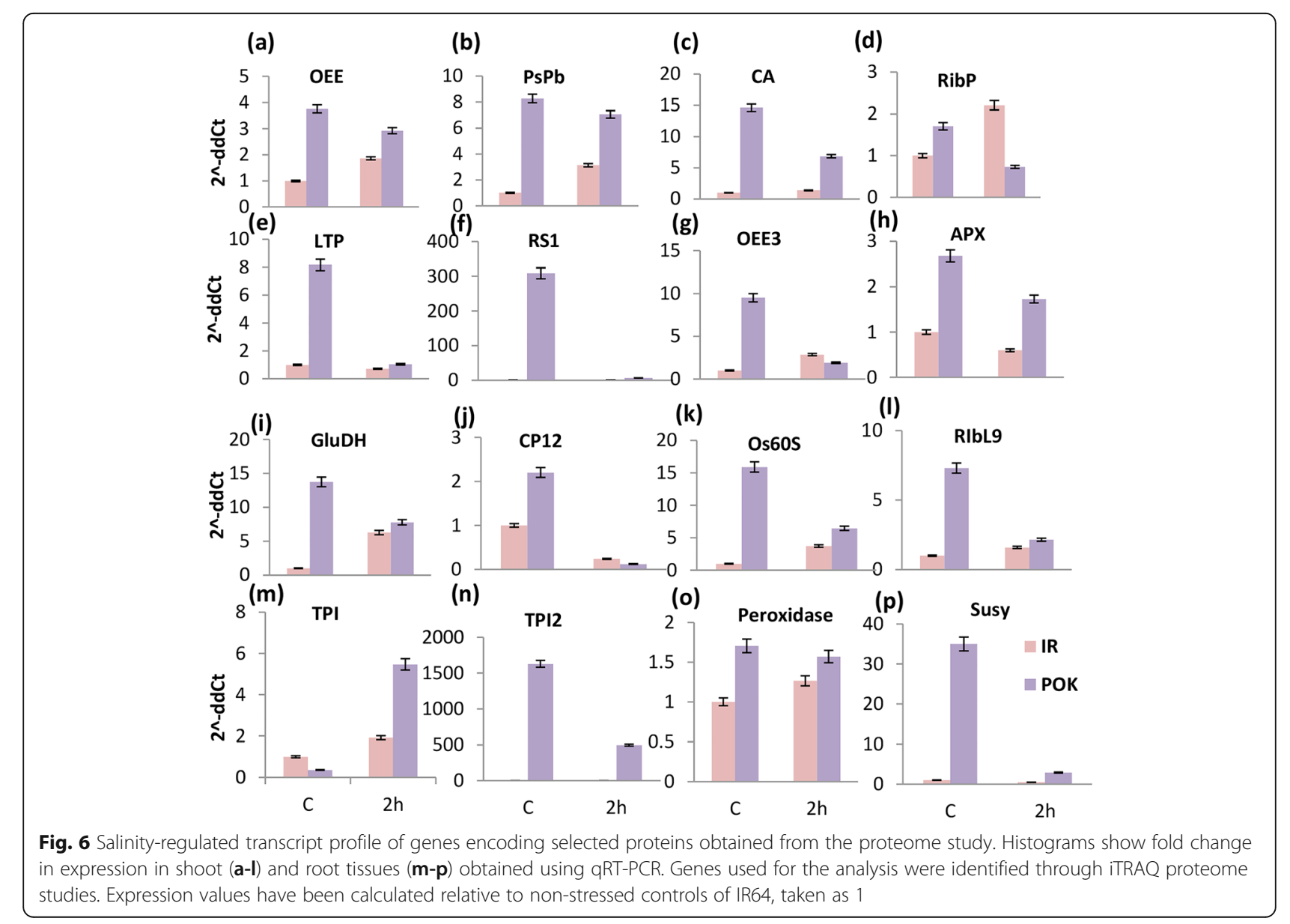


conditions in Pokkali even though its protein levels could not be detected under control conditions (Fig. 6 m-p). Overall, we could observe the differential pattern of gene expression with some genes showing correlations between their protein and transcript profiles.

\section{Protein-protein interaction network among differentially expressed proteins of Pokkali}

To predict the relationship among the differentially expressed proteins, two protein-protein interaction (PPI) networks were created using the differential Pokkali proteome which comprised of both root and shoot proteins. The analysis was carried out using STRING web tool and provided an overview of the differential protein networks operating in Pokkali w.r.t IR64 under control and stress conditions (Fig. 7 a, b). Of the 126 proteins differentially expressed under control conditions in Pokkali root and shoot tissues, 54 proteins were depicted in the network which showed interactions with each other and formed major clusters (Fig. 7a). The photosynthetic protein cluster comprising OEE1, OEE3, PsbP, thylakoid lumen protein and $\mathrm{RuBisCo}$ formed a major module which interacted with the network of metabolic enzymes involved in TCA/calvin cycle such as, transketolase and FBP aldolase (Fig. 7a). Further, stress-responsive genes such as superoxide dismutase, peroxidase, thioredoxin, and glyoxalase were also included in this interaction module, being connected with the above two networks of proteins. Notably, a chaperone protein network was also enriched under control conditions however, under stress, out of the 71 differentially expressed proteins in Pokkali shoot and root tissues, 32 were depicted in the network (Fig. 7b). The protein-protein interaction network of stressed Pokkali proteome retained the photosynthesis-related protein module and included glycolysis/TCA cycle protein network as well (Fig. 7b). In addition to this, proteins involved in RNA binding and translation formed another module, which was not seen under control conditions.

\section{Discussion}

Salinity stress is an important constraint for agriculture affecting food production worldwide. So far, many studies have been undertaken to decipher the intricate processes operating under stress but still more efforts are needed to elucidate the components of stress response and adaptation. In the present work, we have studied the proteomes of Pokkali and IR64 under non-stress conditions as well as in response to short-term salinity stress using iTRAQ. We specifically chose an early, short duration stress $(2 \mathrm{~h})$ for our study, as we believe that some important changes needed for stress adaptation occur during this initial phase and it is during this time that the fate of plant survival is decided. However, it should not mean that later stages of salinity stress are not crucial for plant survival as recovery responses also need to be very efficient to help plants emerge from the stress. In the present study, our focus was to investigate initial phase of salinity response, which is in fact, a state of osmotic shock for the plants wherein, plants suffer more from the detrimental effects of changes in osmolarity rather than the accumulation of $\mathrm{Na}^{+}$ions. $\mathrm{Na}^{+}$accumulation contributes to ion toxicity at much later stages of the salinity response. Further, we have also investigated non-stress conditions to get insights into the pre-existing differences in the proteome of the two genotypes.

Our initial experiments demonstrated that $\mathrm{Na}^{+}$accumulated in the shoot and root of Pokkali and IR64 seedlings after $2 \mathrm{~h}$ of salinity treatment as an indication towards the initiation of the salinity stress, but the increase was found to be more in shoots in IR64 whereas Pokkali showed more $\mathrm{Na}^{+}$accumulation in roots. The capacity to exclude sodium from the shoot is usually an important determinant of salt tolerance in plants (Garthwaite et al. 2005; Kumari et al. 2009). In this context, $\mathrm{Na}^{+}$accumulation pattern in potato varieties suggested a correlation between $\mathrm{Na}^{+}$accumulation and stress tolerance, where the salt-sensitive potato variety Mozart was found to show higher sodium accumulation in leaves than roots and stem than the tolerant Desiree variety (Jaarsma et al. 2013). Though ion toxicity builds up during later stages of salinity stress, but even at $2 \mathrm{~h}$, we could observe a similar pattern of $\mathrm{Na}^{+}$accumulation in the genotypes, being higher in the shoot of salt-sensitive IR64 rice as compared to salt-tolerant Pokkali. Further, we detected higher levels of $\mathrm{H}_{2} \mathrm{O}_{2}$ in roots of Pokkali as compared to IR64 under stress conditions. Higher ROS levels in the system are usually an indicator of oxidative stress but higher levels may also confer ability for the constitutive activation of defense pathways that in turn keeps the tolerant cultivars prepared for adaptation to salt stress conditions (Kaur et al. 2016). On similar lines, a study conducted in salt-sensitive and salt-tolerant varieties of rice have revealed higher $\mathrm{H}_{2} \mathrm{O}_{2}$ and lower superoxide levels in the salt-tolerant varieties as compared to the sensitive ones (Kaur et al. 2016).

Pokkali and IR64 protein profiles revealed the expression-related differences in the two genotypes even under non-stress conditions. Eighty-six proteins were found to be significantly different in their expression pattern in Pokkali shoot tissues with respect to IR64 under control conditions. In roots, around 40 such proteins were identified to be possessing different expression levels in Pokkali and IR64. Importantly, these proteins were enriched in photosynthetic and protein metabolism-related functions in the shoot. For instance, photosynthesis related proteins such as Oxygen-evolving enhancer protein 1, PsbP, thylakoid lumenal $16.5 \mathrm{kDa}$ 


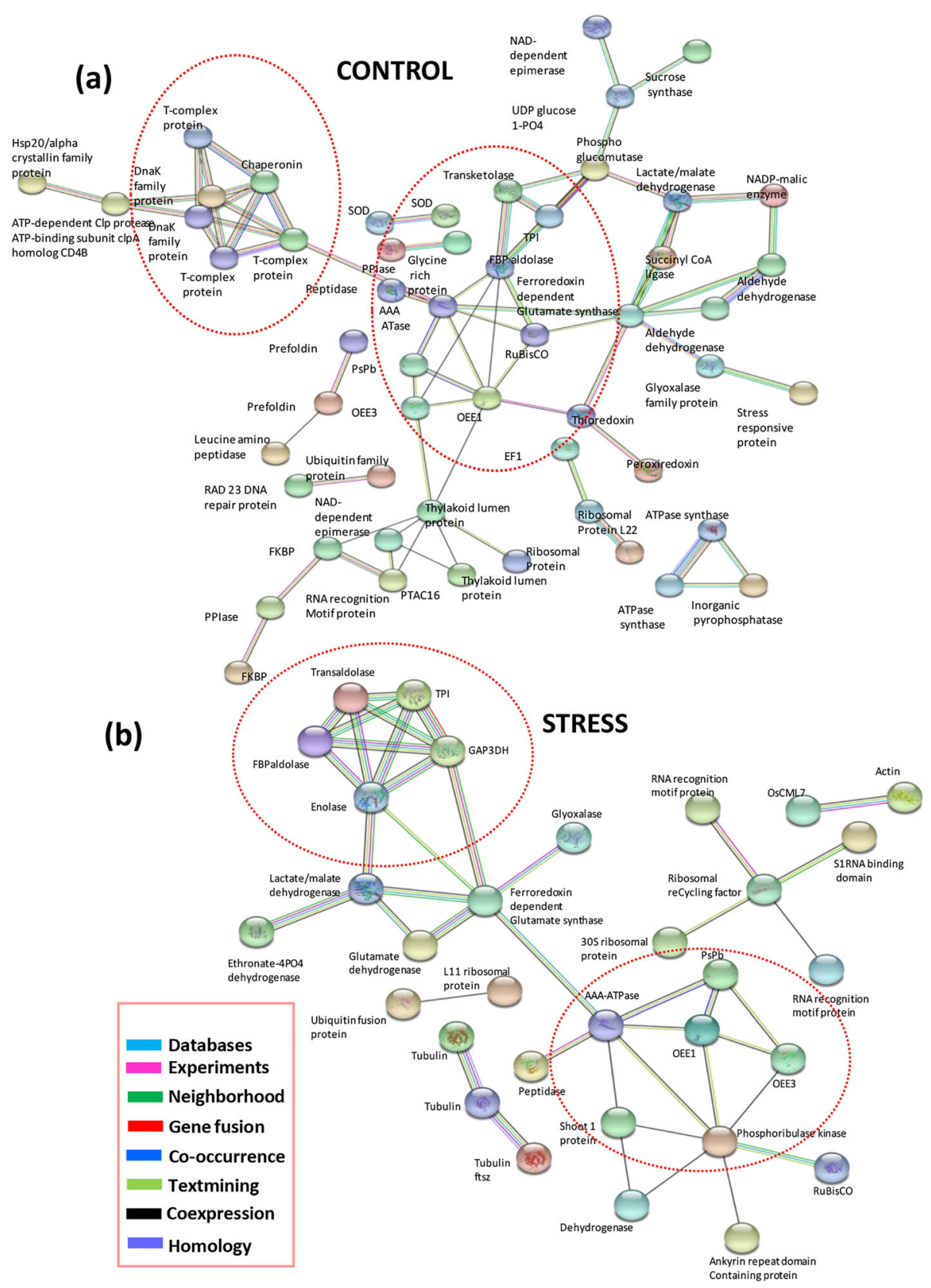

Fig. 7 Protein-protein interaction network of differentially expressed proteins of Pokkali under control (a) and stressed (b) conditions. Network was developed using STRING software (https://string-db.org/). Circles show the major clusters of interacting proteins. Colored lines between the proteins indicate the various types of interaction evidence as denoted in the left corner

proteins were present at higher levels in Pokkali than IR64 under non-stress conditions. In agreement, we have previously shown that Pokkali possesses higher photosynthetic rate than IR64 under non-stress conditions (Lakra et al. 2018). Further, proteins related to stress response such as, superoxide dismutase, ascorbate peroxidase, peptidyl-prolyl cis-trans isomerases, glyoxalase II and thioredoxin were also found to be enriched in Pokkali under non-stress conditions. This is in agreement with the previously reported higher activity of antioxidant machinery in Pokkali in comparison to IR64 under non-stress conditions such as, of superoxide dismutase, glutathione peroxidase, glutathione reductase, glyoxalases and catalase (El-Shabrawi et al. 2010; Lee et al. 2013). In addition, other proteins such as LTPs (Lipid transfer proteins), coproporphyrinogen III oxidase, phytocyanin related protein Pn14, NDPK1, HMG (high mobility group) protein and ferredoxin-dependent 
glutamate synthase also showed a higher expression in Pokkali under control conditions. NDPKs, which are among the oldest known proteins, mainly function in maintaining the metabolic balance between NTPs and NDPs in cells, signal transduction, elongation of rice coleoptile and plant stress response (Hasunuma et al. 2003; Ryu et al. 2005; Dorion et al. 2006). Interestingly, we found around 27 proteins in the shoot proteome of Pokkali to be $>60$-fold higher in expression as compared to IR64 which included several stress responsive candidates.

In root proteome, proteins related to metabolism were enriched under normal conditions indicating high metabolic activity in roots of Pokkali. Proteins such as, triose phosphate isomerase, malate dehydrogenase, succinyl-CoA ligase beta-chain, sucrose synthase and malic enzyme were present at higher levels in Pokkali in comparison to IR64 which may result in the production of higher levels of sugar in roots. In this context, it has been reported that the accumulation of total soluble sugars and sucrose occurs to higher levels in the leaves of salt-sensitive rice variety, Khao Dawk Mali 105 in comparison to salt-tolerant Pokkali both under non-stress and stress conditions (Pattanagul and Thitisaksakul 2008). However, authors did not measure sugar level in roots. Further, Pokkali accumulates starch instead of sucrose in response to stress which may be a way of partitioning sugars to avoid metabolic alterations in response to salinity stress (Pattanagul and Thitisaksakul 2008). Around 5 proteins in root proteome of Pokkali had $>60$-fold abundance when compared to IR64.

Under salinity stress, levels of proteins related to photosynthesis such as, oxygen-evolving enhancer protein 1 , PsbP and oxygen evolving enhancer protein 3 remained elevated in the shoots of Pokkali. Further, proteins such as, Ribulose bisphosphate carboxylase large chain 1 and Ribulose bisphosphate carboxylase/oxygenase activase, were also increased under stress, in agreement with the observed increased photosynthetic activity in Pokkali under stress (Lakra et al. 2018). In addition, other proteins such as ankyrin repeat domain protein 2, LEA, OsCML7, ABA/WDS induced protein, inorganic pyrophosphatase, carbonic anhydrase and LTP were also found to be highly expressed under stress. The ankyrin repeat domain is present in some inward rectifying channels in plants which are involved in the low-affinity $\mathrm{K}^{+}$transport (Fox and Guerinot 1998). Further, LTPs transport cutin or wax to the plasma membrane as a protection against water loss. Cutin is in fact, one of the main components of the plant cuticle which functions as a barrier against water loss.

Notably, a glutamate dehydrogenase protein was also highly elevated in Pokkali under stress. This enzyme acts as an important link between TCA cycle and amino acids metabolism and appears to have a significant role in the provision of carbon skeleton under conditions of carbon limitation (Athwal et al. 1997). A similar increase in the levels of this protein has also been reported in salt-tolerant rice varieties, CSR- 1 and CSR-3 in comparison to salt-sensitive Ratna and Jaya varieties (Kumar et al. 2000). Another protein CDGSH iron sulfur protein (also referred to as mitoNEET) was found to be higher under stress in pokkali. CDGSH iron sulfur domains are generally located in the mitochondrial membranes and serve as transport channels for electron gradient regulation and iron transport (Lin et al. 2011). These proteins play a key role in modulating maximal capacity for electron transport and oxidative phosphorylation and are even involved in Fe-S cluster shuttling and in redox reactions.

Furthermore, a ferredoxin-dependent glutamate synthase protein showed 64-fold increase in Pokkali in comparison to IR64 under control conditions. It is known to be involved in glutamate biosynthesis in leaf and is also required for the re-assimilation of ammonium ions generated during photorespiration. In addition, we also found proteins such as, coproporphyrinogen III oxidase, lipid transfer protein (LTP), clathrin protein, RAD23, HMG transcription factor and ribosomal protein S11, to be highly expressed in Pokkali. The coproporphyrinogen III oxidase is involved in heme and chlorophyll biosynthesis and high mobility group (HMG) proteins play key functions in replication, transcription and nucleosome assembly.

In roots, a few proteins which showed altered levels under stress included peroxidases and TPI. Both these proteins have been known to be important for stress response. In fact, TPI has been shown to be regulated by methylglyoxal (MG), a toxic byproduct of glycolysis whose levels increase under stress (Sharma et al. 2012). MG induces TPI activity, which by metabolizing triose sugars prevents accumulation of MG in the system. Hence, TPI plays an important role in stress alleviation in plants by limiting MG levels (Sharma et al. 2012). Expression pattern of few proteins obtained from this analysis correlated well with those of our previous study. Proteins such as, oxygen-evolving enhancer protein 1, ribulose bisphosphate carboxylase large chain precursor, PsbP, ribose-5-phosphate isomerase A, superoxide dismutase, etc. were found through both iTRAQ (present study) and two-dimensional gel electrophoresis (Lakra et al. 2018), to be induced at $2 \mathrm{~h}$ in response to salinity stress. Determination of transcript levels of few proteins obtained from the present analysis revealed correlation in the transcript and protein expression pattern of some proteins.

Overall through this study, we could get some important insights into the differences in proteomes of salt-tolerant Pokkali and salt-sensitive IR64 under both normal and stress conditions. To summarize, Additional file 5: Figure S3 provides an overview of the differentially 
expressed proteins of Pokkali under both control and stressed conditions. The results indicated that most of these proteins were engaged in light reaction, redox related processes and stress responsive process. Our results suggest that Pokkali maintains a high activity of vital pathways such as, photosynthesis and of stress-responsive proteins, even under non-stress conditions which allow its survival and better adaptation under stress.

\section{Conclusions}

Salinity stress poses a major risk to agriculture and hence, elucidating response mechanisms of plants to stress becomes necessary for understanding the stress adaptation dynamics and for raising tolerant crops to minimize the "yield gap". To this end, we studied the response of salt-tolerant and salt-sensitive rice genotypes viz. Pokkali and IR64 to short-term salinity stress. Our studies conclude that Pokkali showed well preparedness to face stress conditions as the proteins otherwise, induced in response to stress in IR64, are naturally highly expressed in Pokkali even under control conditions, and upon encountering stress conditions, this pro-active stress machinery combats adverse conditions in a more efficient manner as compared to IR64.

\section{Material and methods}

\section{Plant material and growth conditions}

Seeds of Rice (O. sativa L. cv. IR64 and Pokkali) were surface sterilized and germinated for $48 \mathrm{~h}$ at $28^{\circ} \mathrm{C}$ under hydroponic setup in a growth chamber as described earlier (Lakra et al. 2018). After 10 days of growth, seedlings were divided into two sets, of which one set was transferred to Yoshida medium containing $200 \mathrm{mM} \mathrm{NaCl}$ while the other set was used as control and so remained in the Yoshida medium (1972). After $2 \mathrm{~h}$ of $\mathrm{NaCl}$ treatment, root and shoot tissues of 20 seedlings of each group were harvested for proteome analysis, qRT-PCR analysis, and physiological studies.

\section{Determination of $\mathrm{Na}^{+}$and $\mathrm{K}^{+}$content}

One hundred milligrams tissue (roots or shoots) harvested from control and $\mathrm{NaCl}$ treated plants, was digested in $0.1 \% \mathrm{HNO}_{3}$ and the concentration of $\mathrm{Na}^{+}$ and $\mathrm{K}^{+}$was recorded by AAS (atomic absorption spectroscopy) as described earlier (Kumar et al. 2009).

\section{Relative ion leakage}

Ion leakage was measured as described by Bajji et al. (2002). Briefly, leaf tissues harvested from the control and $\mathrm{NaCl}$ treated plants were first washed with distilled water to remove any ions adhering to the surface. One hundred milligrams tissue was then dipped into the de-ionized water and incubated at $37^{\circ} \mathrm{C}$ for $2 \mathrm{~h}$, following which, electrical conductivity $\left(\mathrm{E}_{1}\right)$ of the solution was measured using a conductivity meter (ELEINS, Inc., India). After measuring $E_{1}$, samples were autoclaved for $15 \mathrm{~min}$. Total conductivity $\left(E_{2}\right)$ was measured once the samples cooled down to room temperature. Relative electrical conductivity was calculated using the formula: Ion leakage percentage $=E_{1} / E_{2}{ }^{*} 100$.

\section{Cell viability test}

Cell viability of roots tissues was determined as described earlier by Sanevas et al. (2007). Fresh root samples were first stained with Evans Blue dye $(0.25 \%)$ for $15 \mathrm{~min}$ at room temperature followed by washing in distilled water for $45 \mathrm{~min}$ to remove any surface-bound dye. Next, Evans Blue stain taken up by the dead cells was extracted at $55^{\circ}$ $\mathrm{C}$ for $1 \mathrm{~h}$ using 1\% ( $w / v)$ SDS. Finally, absorbance was measured at $600 \mathrm{~nm}$ to determine the amount of Evans Blue uptake by the roots.

\section{Detection of hydrogen peroxide $\left(\mathrm{H}_{2} \mathrm{O}_{2}\right)$ by DAB staining} For the detection of $\mathrm{H}_{2} \mathrm{O}_{2}$, roots of seedlings were incubated in 3,3-diaminobenzidine (DAB; $1 \mathrm{mg} / \mathrm{ml}$ concentration) staining solution for $2-4 \mathrm{~h}$ under the dark conditions followed by washing to remove the extra dye before viewing under microscope (Daudi and O'Brien 2012).

\section{Confocal microscopy for detection of sodium ions using CoroNa green dye}

Root samples were visualized using CoroNa Green dye as described by Gupta et al. (2018). A confocal laser scanning microscope (Fluoview FV300; Olympus, Tokyo, Japan) with a 488-nm excitation and 505-525 nm emission wavelength was used. Equal photomultiplier tube (PMT) settings were used to visualize images which prevented artifacts for each sample set. Average fluorescence intensity was measured by subtracting the background of corresponding image for each sample.

iTRAQ labeling, strong cation exchange fractionation and reverse phase nanoLC

Protein samples were processed for iTRAQ using the iTRAQ Reagents Multiplex kit (Applied Biosystems/MDS Sciex, Foster City, CA, USA). Twenty milligrams protein samples of IR64 and Pokkali obtained from either control or $\mathrm{NaCl}(200 \mathrm{mM})$ treated plants were labeled with different iTRAQ reagents. IR64 samples (control and $\mathrm{NaCl}$-treated) were labeled with 114 and Pokkali (control and $\mathrm{NaCl}$-treated) by 117 iTRAQ reagents. After labelling, control samples of both IR64 and Pokkali were pooled and similar pooling was done for $\mathrm{NaCl}$-treated labelled samples. This was followed by vacuum-drying and ultimately samples were subjected to strong cation exchange (SCX) fractionation on the Agilent 1100 HPLC system using a PolySulfoethyl column $(4.6 \times 100 \mathrm{~mm}, 5 \mu \mathrm{m}, 300 \mathrm{~A})$. However, before SCX fractionation, labelled peptides were first desalted using a 
Strata-X $33 \mu \mathrm{m}$ polymeric reversed phase column (Phenomenex) followed by resuspension in buffer containing $10 \mathrm{mM}$ $\mathrm{KH}_{2} \mathrm{PO}_{4}$ in $10 \%$ acetonitrile, $\mathrm{pH} 3.0$. After fractionation, peptides were eluted with a linear gradient of $0-400 \mathrm{mM}$ $\mathrm{KCl}$. Eight fractions were collected and again desalted on Strata-X columns.

For second dimension reverse phase nanoLC, fractions were loaded onto a C18 PepMap100 column, a $3 \mu \mathrm{m}$ column (LC Packing) running on an Ultimate 3000 nano HPLC system (Dionex). Peptides were resolved with a gradient of $10-40 \%$ acetonitrile (prepared in $0.1 \%$ trifluoroacetic acid) and fractions were spotted using a ProBot robotic spotter (LC Packings) on the AnchorChip MALDI plates. The spots were analysed by 5800 MALDI TOF/TOF Analyzer.

\section{Data analysis}

Spectral data was analysed using ProteinPilot ${ }^{\mathrm{mw}} 4.0$ Software (AB Sciex) against the UniProt rice database. The database containing 2,88,134 protein sequences was used to extract peptide and protein data at $>95 \%$ confidence levels and high top one peptide rank filters. False discovery rate (FDR) was determined using Proteomics System Performance Evaluation Pipeline (PSPEP) feature of ProteinPilot ${ }^{\mathrm{Tm}}$ software. For achieving high confidence identifications, target FDR threshold was set at $1 \%$. Relative quantitation of proteins was based on the relative intensities of reporter ions released during the MS/MS peptide fragmentation. In order to determine the relative protein contents of the samples, only unique peptides for each identified protein were taken.

\section{Bioinformatics analysis}

The identified proteins were annotated using Gene Ontology (GO) database (https://www.blast2go.com/) and assigned protein functions using the protein function databases, InterPro (http://www.ebi.ac.uk/interpro/) or Pfam (https://pfam.xfam.org//) and finally confirmed by MSU v7.0 rice database (http://rice.plantbiology.msu.edu/). Clustering was performed based on fold-induction expression values from control (Pok/ IR64) and stress (Pok/IR64) samples using the Multi Experiment Viewer software (The Institute for Genomic Research). The data was clustered using Pearson correlation (Romijn et al. 2015). A PPI (Protein-Protein Interaction) network was constructed using STRING 10.5 tool with a confidence level of 0.7 (https://string-db.org). To analyze the metabolic and signaling changes in protein expression under control and stress conditions, a MapMan tool (http://mapman.gabipd.org/web/guest/ mapman) (Thimm et al. 2004) was used.

Real-time quantitative reverse transcription PCR

Total RNA was isolated, cDNA was prepared and qRT-PCR was performed as described earlier (Soda et al.
2013). Primers used for the analysis have been listed as Additional file 6: Table S3. The rice elongation factor $(\mathrm{eEF} 1 \alpha)$ was used as a house-keeping gene for data normalization. For every sample, two biological replicates were used, each having three technical replicates $(n=6)$.

\section{Statistical analysis}

All the data (from three replicates) from physio-chemical analysis, were subjected to ANOVA (analysis of variance) using the GraphPad InStat3 software. For iTRAQ, differentially expressed proteins with at least 1.5 -fold change and $p$ value $<0.05$ were selected.

\section{Additional files}

Additional file 1: Figure S1. Evan blue staining of the roots of Pokkali and IR64 seedlings in response to $2 \mathrm{~h}$ of salinity stress. (TIFF $314 \mathrm{~kb}$ )

Additional file 2: Figure S2. DAB staining of the roots of Pokkali and IR64 seedlings in response to $2 \mathrm{~h}$ of salinity stress. (TIF $10980 \mathrm{~kb}$ )

Additional file 3: Table S1. Highly differentially expressed proteins (>60 fold) in shoot and root tissues. (XLSX $18 \mathrm{~kb}$ )

Additional file 4: Table S2. Differentially expressed proteins in shoot tissues of Pokkali w.r.t IR64 which are commonly appearing under non stress and stress conditions. (XLSX $13 \mathrm{~kb}$ )

Additional file 5: Figure S3. Depiction of differentially expressed proteins on metabolic pathways using Mapman. Individual elements in the metabolic overview, stress response and redox overview are indicated by solid red rectangular boxes. Rectangular boxes indicate over-represented Mapman functional groups under control and stress conditions in Pokkali with respect to IR64. (TIFF 1525 kb)

Additional file 6: Table S3. List of RTPCR primers and their sequences (5'to 3 ') used in this study. (XLSX $10 \mathrm{~kb}$ )

\section{Acknowledgements}

$\mathrm{NL}$ is thankful to University Grant Commission for providing Dr. D. S. Kothari Fellowship and CK acknowledges Department of Science and Technology (DST) for the funds received from the DST-INSPIRE Faculty award.

\section{Funding}

The research work was supported by the grant (BT/PR11677/PBD/16/832/ 2008) received from Department of Biotechnology (DBT) and funds received from DST-PURSE, India to AP.

\section{Availability of data and materials}

The datasets supporting this article are included in the article and in the additional files.

\section{Authors' contributions}

NL performed experiments, analyzed data and helped in manuscript writing. CK performed data analysis and wrote the manuscript. SLS-P helped in designing the study and manuscript writing. AP conceived and designed the study and finalized the manuscript experiments. All authors read and approved the final manuscript.

Ethics approval and consent to participate Not applicable.

Consent for publication Not applicable.

Competing interests

The authors declare that they have no competing interests. 


\section{Publisher's Note}

Springer Nature remains neutral with regard to jurisdictional claims in published maps and institutional affiliations.

\section{Author details}

${ }^{1}$ Stress Physiology and Molecular Biology Laboratory, School of Life Sciences, Jawaharlal Nehru University, New Delhi 110067, India. ²Plant Stress Biology, International Centre for Genetic Engineering and Biotechnology, Aruna Asaf Ali Road, New Delhi 110067, India.

Received: 15 September 2018 Accepted: 11 December 2018 Published online: 30 January 2019

\section{References}

Athwal GS, Pearson J, Laurie S (1997) Regulation of glutamate dehydrogenase activity by manipulation of nucleotide supply in Daucus carota suspension cultures. Physiol Plant 101:503-509

Bajji M, Kinet JM, Lutts S (2002) The use of the electrolyte leakage method for assessing cell membrane stability as a water stress tolerance test in durum wheat. Plant Growth Regul 36:61-70

Damaris RN, Li M, Liu Y, Chen X, Murage H, Yang P (2016) A proteomic analysis of salt stress response in seedlings of two African rice cultivars. Biochim Biophys Acta (BBA)-proteins. Proteomics 1864:1570-1578

Daudi A, O'Brien JA (2012) Detection of hydrogen peroxide by DAB staining in Arabidopsis leaves. Bio Protocol 2:e263

Dorion S, Matton DP, Rivoal J (2006) Characterization of a cytosolic nucleoside diphosphate kinase associated with cell division and growth in potato. Planta 224:108-124

El-Shabrawi H, Kumar B, Kaul T, Reddy MK, Singla-Pareek SL, Sopory SK (2010) Redox homeostasis, antioxidant defense, and methylglyoxal detoxification as markers for salt tolerance in Pokkali rice. Protoplasma 245:85-96

Fageria NK (2007) Yield physiology of rice. J Plant Nutr 30:843-879

Fox TC, Guerinot ML (1998) Molecular biology of cation transport in plants. Annu Rev Plant Physiol Plant Mol Biol 49:669-696

Garthwaite AJ, von Bothmer R, Colmer TD (2005) Salt tolerance in wild Hordeum species is associated with restricted entry of $\mathrm{Na}^{+}$and $\mathrm{Cl}^{-}$into the shoots. J Exp Bot 56:2365-2378

Ghosh D, Li Z, Tan XF, Lim TK, Mao Y, Lin Q (2013) ITRAQ based quantitative proteomics approach validated the role of calcyclin binding protein (CacyBP) in promoting colorectal cancer metastasis. Mol Cell Proteomics 12:1865-1880

Gupta BK, Sahoo KK, Ghosh A, Tripathi AK, Anwar K, Das P, Singh AK, Pareek A, Sopory SK, Singla-Pareek SL (2018) Manipulation of glyoxalase pathway confers tolerance to multiple stresses in rice. Plant Cell Environ 41:1186-1200

Hasunuma K, Yabe N, Yoshida Y, Ogura Y, Hamada T (2003) Putative functions of nucleoside diphosphate kinase in plants and fungi. $J$ Bioenerg Biomembr 35:57-65

Jaarsma R, de Vries RSM, de Boer AH (2013) Effect of salt stress on growth, $\mathrm{Na}^{+}$ accumulation and proline metabolism in potato (Solanum tuberosum) cultivars. PLoS One 8:e60183.

Joshi R, Sahoo KK, Tripathi AK, Kumar R, Gupta BK, Pareek A, Singla-Pareek SL (2018) Knockdown of an inflorescence meristem-specific cytokinin oxidaseOsCKX2 in rice reduces yield penalty under salinity stress condition. Plant Cell Environ 41:936-946

Kaur N, Dhawan M, Sharma I, Pati PK (2016) Interdependency of reactive oxygen species generating and scavenging system in salt sensitive and salt tolerant cultivars of rice. BMC Plant Biol 16:131

Kim SG, Kim ST, Kang SY, Wang Y, Kim W, Kang KY (2008) Proteomic analysis of reactive oxygen species (ROS)-related proteins in rice roots. Plant Cell Rep 27:363-375

Kumar G, Purty RS, Sharma MP, Singla-Pareek SL, Pareek A (2009) Physiological responses among Brassica species under salinity stress show strong correlation with transcript abundance for SOS pathway-related genes. J Plant Physiol 166:507-520

Kumar RG, Shah K, Dubey RS (2000) Salinity induced behavioural changes in malate dehydrogenase and glutamate dehydrogenase activities in rice seedlings of differing salt tolerance. Plant Sci 156:23-34

Kumari S, Sabharwal VP, Kushwaha HR, Sopory SK, Singla-Pareek SL, Pareek A (2009) Transcriptome map for seedling stage specific salinity stress response indicates a specific set of genes as candidate for saline tolerance in Oryza sativa L. Funct Integr Genomics 9:109-123
Lakra N, Kaur C, Anwar K, Singla-Pareek SL, Pareek A (2018) Proteomics of contrasting rice genotypes: identification of potential targets for raising crops for saline environment. Plant Cell Environ 41:947-969

Lee MH, Cho EJ, Wi SG, Bae H, Kim JE, Cho JY, Lee S, Kim JH, Chung BY (2013) Divergences in morphological changes and antioxidant responses in salttolerant and salt-sensitive rice seedlings after salt stress. Plant Physiol Biochem 70:325-335

Lin J, Zhang L, Lai S, Ye K (2011) Structure and molecular evolution of CDGSH iron-sulfur domains. PLoS One 6:e24790

Moradi F, Ismail AM (2007) Responses of photosynthesis, chlorophyll fluorescence and ROS scavenging systems to salt stress during seedling and reproductive stages in rice. Ann Bot 66:1161-1173

Munns R, Tester M (2008) Mechanisms of salinity tolerance. Annu Rev Plant Biol 59:651-681

Nutan KK, Kushwaha HR, Singla-Pareek SL, Pareek A (2017) Transcription dynamics of Saltol QTL localized genes encoding transcription factors, reveals their differential regulation in contrasting genotypes of rice. Funct Integr Genomics 17:69-83

Pareek A, Sopory SK, Bohnert HJ, Govindjee (2010) Abiotic Stress Adaptation in Plants. Physiological, Molecular and Genomic Foundation Springer, Berlin

Pattanagul W, Thitisaksakul M (2008) Effect of salinity stress on growth and carbohydrate metabolism in three rice (Oryza sativa $\mathrm{L}$ ) cultivars differing in salinity tolerance. Indian J Exp Biol 46:736-742

Romijn EP, Christis C, Wieffer M, Gouw JW, Fullaondo A, van der Sluijs P, Braakman I, Heck AJ (2015) Expression clustering reveals detailed coexpression patterns of functionally related proteins during $B$ cell differentiation: a proteomic study using a combination of one-dimensional gel electrophoresis, LC-MS/MS, and stable isotope labeling by amino acids in cell culture (SILAC). Mol Cell Proteomics 4:1297-1310

Ryu JS, Kim Jl, Kunkel T, Kim BC, Cho DS, Hong SH, Kim SH, Fernández AP, Kim Y, Alonso JM, Ecker JR, Nagy F, Lim PO, Song PS, Schäfer E, Nam HG (2005) Phytochrome-specific type 5 phosphatase controls light signal flux by enhancing phytochrome stability and affinity for a signal transducer. Cell 120:395-406

Sanevas N, Sunohara Y, Matsumoto H (2007) Characterization of reactive oxygen species-involved oxidative damage in Hapalosiphon species crude extracttreated wheat and onion roots. Weed Biol Manag 7:172-177

Shankar R, Bhattacharjee A, Jain M (2016) Transcriptome analysis in different rice cultivars provides novel insights into desiccation and salinity stress responses. Sci Rep 6:23719. https://doi.org/10.1038/srep23719

Sharma S, Mustafiz A, Singla-Pareek SL, Shankar Srivastava P, Sopory SK (2012) Characterization of stress and methylglyoxal inducible triose phosphate isomerase (OscTPI) from rice. Plant Signal Behav 7:1337-1345

Soda N, Kushwaha HR, Soni P, Singla-Pareek SL, Pareek A (2013) A suite of new genes defining salinity stress tolerance in seedlings of contrasting rice genotypes. Funct Integr Genomics 13:351-365

Thimm O, Bläsing O, Gibon Y, Nagel A, Meyer S, Krüger P, Selbig J, Müller LA Rhee SY, Stitt M (2004) MAPMAN: a user-driven tool to display genomics data sets onto diagrams of metabolic pathways and other biological processes. Plant J 37:914-939

Thomson MJ, de OM, Egdane J, Rahman MA, Sajise AG, Adorada DL, Singh RK, Gregorio GB, Ismail AM (2010) Characterizing the Saltol quantitative trait locus for salinity tolerance in Rice. Rice 3:148-160

Vijayan R (2016) Pokkali rice cultivation in Kerala. Agric Update:11329-11333.

Waziri A, Kumar P, Purty RS (2016) Saltol QTL and Their role in salinity tolerance in Rice. Austin J Biotechnol Bioeng 3(3):1067

Xu J, Lan H, Fang H, Huang X, Zhang H, Huang J (2015) Quantitative proteomic analysis of the rice (Oryza sativa L) salt response. PLoS One 10:e0120978 https://doi.org/10.1371/journal.pone.0120978

Yoshida S, Forno DA, Cock JH, Gomez KA (1972) Laboratory manual for physiological studies of Rice. International Rice Research Institute, Manila

Zieske LR (2006) A perspective on the use of iTRAQ ${ }^{\mathrm{TM}}$ reagent technology for protein complex and profiling studies. J Exp Bot 57:1501-1508 